\title{
Advances in tenascin-C biology
}

\author{
Kim S. Midwood • Thomas Hussenet • \\ Benoit Langlois · Gertraud Orend
}

Received: 8 July 2011/Revised: 19 July 2011/ Accepted: 19 July 2011/Published online: 5 August 2011

(C) The Author(s) 2011. This article is published with open access at Springerlink.com

\begin{abstract}
Tenascin-C is an extracellular matrix glycoprotein that is specifically and transiently expressed upon tissue injury. Upon tissue damage, tenascin- $\mathrm{C}$ plays a multitude of different roles that mediate both inflammatory and fibrotic processes to enable effective tissue repair. In the last decade, emerging evidence has demonstrated a vital role for tenascin-C in cardiac and arterial injury, tumor angiogenesis and metastasis, as well as in modulating stem cell behavior. Here we highlight the molecular mechanisms by which tenascin- $\mathrm{C}$ mediates these effects and discuss the implications of mis-regulated tenascin-C expression in driving disease pathology.
\end{abstract}

Keywords Tenascin-C · Cardiac injury ·

Vascular imaging $\cdot$ Stem cells $\cdot$ Tumor metastasis

$\begin{array}{ll}\text { Abbreviations } \\ \text { AD1 } & \text { Additional domain 1 } \\ \text { cFN } & \text { Cellular fibronectin } \\ \text { CRT } & \text { Cardiac resyn chronization therapy } \\ \text { CNS } & \text { Central nervous system } \\ \text { CMI } & \text { Cryo-coagulation induced MI }\end{array}$

T. Hussenet and B. Langlois contributed equally to this work.

K. S. Midwood ( $\square)$

Kennedy Institute of Rheumatology Division, Faculty of

Medicine, NDORMS, Oxford University, 65 Aspenlea Road,

Hammersmith, London W6 8LH, UK

e-mail: kim.midwood@kennedy.ox.ac.uk

T. Hussenet · B. Langlois · G. Orend $(\bowtie)$

Institut National de la Santé et de la Recherche Médicale U682,

Faculté de Médicine, Université Strasbourg, UMR-S682,

Strasbourg, CHRU Strasbourg, Service biologie moléculaire,

3 avenue Molière, 67200 Strasbourg, France

e-mail: gertraud.orend@inserm.u-strasbg.fr

$\begin{array}{ll}\text { DKK } & \text { Dickkopf } \\ \text { EDA/EDB } & \text { Extradomain A and B from cFN } \\ \text { EDNR } & \text { Endothelin receptor } \\ \text { ESC } & \text { Embryonic stem cells } \\ \text { EGF-L } & \text { Epidermal growth factor-like repeats } \\ \text { ECM } & \text { Extracellular matrix } \\ \text { FBG } & \text { Fibrinogen-like globe } \\ \text { FNIII } & \text { Fibronectin type III-like repeats } \\ \text { GBM } & \text { Glioblastoma } \\ \text { HGF } & \text { Hepatocyte growth factor } \\ \text { HNK } & \text { Human natural killer-1 } \\ \text { LV } & \text { Left ventricular } \\ \text { LVH } & \text { Left ventricular hypertrophy } \\ \text { MEF } & \text { Murine embryonic fibroblasts } \\ \text { MMPs } & \text { Matrix metalloproteases } \\ \text { MCT } & \text { Monocrotaline } \\ \text { MI } & \text { Myocardial infarction } \\ \text { NSC } & \text { Neural stem cells } \\ \text { NB } & \text { Neuroblastoma } \\ \text { PDGF } & \text { Platelet-derived growth factor } \\ \text { PyMT } & \text { Polyoma virus middle T antigen } \\ \text { OP } & \text { Oligodendrocyte progenitors } \\ \text { RBPJk } & \text { Recombination signal-binding protein for } \\ & \text { immunoglobulin kappa J region } \\ \text { RMI } & \text { Reperfusion-induced MI } \\ \text { RV } & \text { Right ventricular remodeling } \\ \text { SIP } & \text { Small immunoprotein } \\ \text { SMC } & \text { Smooth muscle cells } \\ \text { Sox4 } & \text { Sex-determining region Y-box 4 } \\ \text { TAM } & \text { Tumor-associated macrophages } \\ \text { TEC } & \text { Tumor-derived endothelial cells } \\ \text { TGF- } \beta & \text { Transforming growth factor } \beta 1 \\ \text { TNC } & \text { Tenascin-C } \\ \text { VEGF } & \text { Vascular endothelial growth factor } \\ \text { vWF } & \text { von Willebrand factor } \\ & \\ & \end{array}$




\section{Introduction}

Tenascin- $\mathrm{C}$ is a large hexameric extracellular glycoprotein. The founding member of a family of four tenascins, it is unique in its distinct pattern of expression. Little or no tenascin- $\mathrm{C}$ is detected in healthy adult tissues. It is transiently re-expressed upon tissue injury, and down-regulated after tissue repair is complete [1]. Tenascin-C is a multimodular protein comprising four distinct domains: an assembly domain, a series of epidermal growth factor-like repeats (EGF-L), a series of fibronectin type III-like repeats (FNIII), and a C-terminal fibrinogen-like globe (FBG). Each of these domains can interact with a different subset of binding partners, including cell surface receptors and other extracellular components (Fig. 1) [2]. By virtue of this domain organization, tenascin- $\mathrm{C}$ is an extraordinarily pleiotropic molecule and mediates a wide range of functions during tissue injury. Here we focus on recent discoveries, areas in which significant advances have been made in our understanding of the action of tenascin- $\mathrm{C}$ in cardiac and arterial injury, tumor angiogenesis, and stem cell biology.

\section{New clinical indications: tenascin- $\mathrm{C}$ in cardiac pathology}

Cardiovascular diseases such as myocardial infarction (MI), hypertension, hypertrophy, or heart failure are all accompanied by changes in the composition of the cardiac extracellular matrix (ECM). These dynamic alterations not only determine the mechanical properties of the damaged heart but also directly modulate the inflammatory and reparative response (reviewed in [3]). Tenascin-C is expressed in the heart in the early embryo where it contributes to the development of the myocardium, valves, and coronary vessels $[4,5]$. The heart develops normally in tenascin-C knockout mice [5-7], suggesting that compensatory mechanisms for tenascin- $\mathrm{C}$ absence during cardiogenesis exist. Tenascin- $\mathrm{C}$ is not found in healthy adult heart tissues [8], except at the chorda tendineae of papillary muscles [9] and at the base of valve leaflets [4]. However, it is re-expressed upon cardiac injury and is found at high levels in a variety of cardiac diseases where the level of expression appears to be a reliable biomarker of disease progression and poor patient prognosis. Emerging evidence has highlighted a number of novel roles for tenascin-C during cardiac repair.

\section{Tenascin-C expression during cardiac injury}

Cardiac injury, for example damage and death of myocardium caused by ischemia and oxygen deprivation during MI, invokes an immediate repair response. Cardiac repair proceeds via an acute inflammatory response to clear tissue debris, followed by tissue deposition and remodeling, which forms a collagenous scar to replace lost or damaged tissue. Prompted by studies that demonstrated early and transient expression of tenascin-C during inflammation and

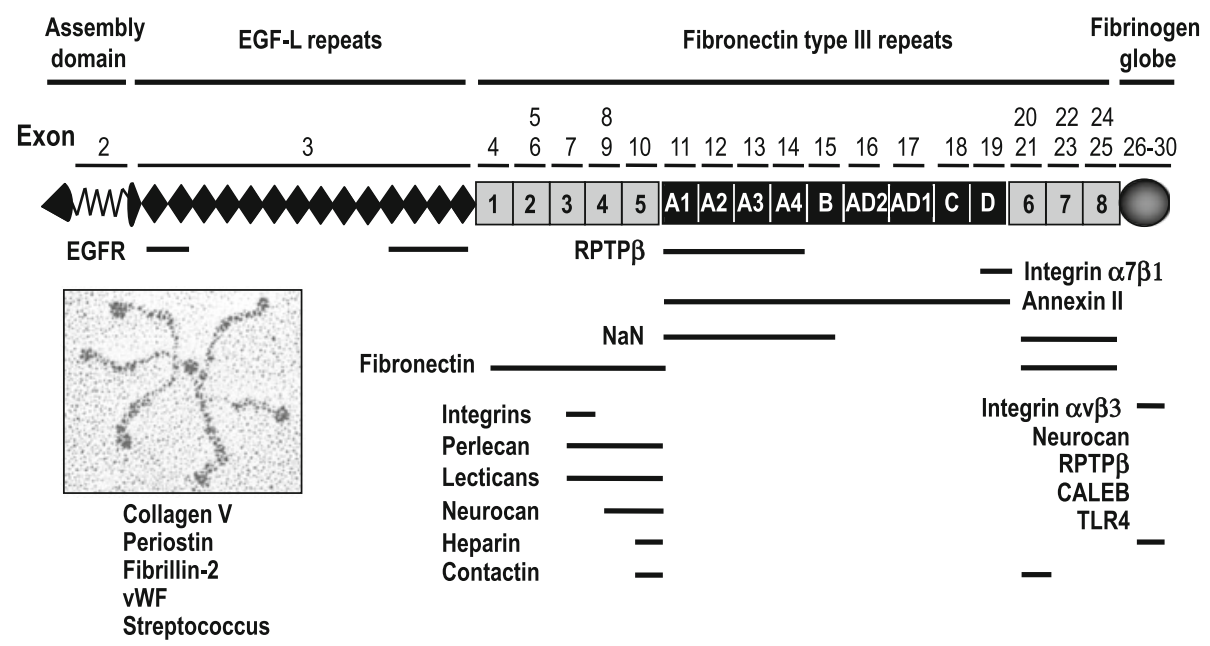

Fig. 1 The modular structure of tenascin-C and the known binding partners of each tenascin domain. Tenascin- $\mathrm{C}$ is a hexameric extracellular glycoprotein. The appearance of purified tenascin-C protein upon electron microscopy is shown. Each tenascin-C monomer comprises four distinct domains: an assembly domain, EGF-L, constant (grey) and alternatively spliced (black) FNIII repeats, and the $\mathrm{C}$-terminal FBG. The exon/intron structure of the human tenascin-C gene on chromosome $9 \mathrm{q} 33$ is depicted schematically based on analysis of sequence entries in the EMBL sequence data bank. Tenascin-C-interacting molecules are shown at the bottom of the figure. CALEB, chicken acidic leucine-rich EGF-like domain containing brain protein; EGFR, epidermal growth factor receptor; $\mathrm{NaN}$, sodium channel subunit $\beta 2$; RPTP $\zeta / \beta$, receptor protein tyrosine phosphatase $\zeta / \beta$ (image modified from Midwood and Orend 2010) 
fibrosis in dermal wound healing (reviewed in [1]), tenascin-C localization during myocardial repair has also been examined. Immunohistochemical analysis of myocardium from patients from $6 \mathrm{~h}$ to 17 years following MI revealed that tenascin- $C$ was induced 4-6 days post infarction at the edges of tissue injury. Expression shifted from the margin to the center of the damaged area 2-3 weeks post-infarction and by 4 weeks, no tenascin- $\mathrm{C}$ was detected [8]. Thus an early and transient expression of tenascin-C, returning to basal levels by the time the collagen scar has formed, is common to both dermal and myocardial injury. The appearance of tenascin-C post MI paralleled that of fibronectin deposition with one exception; tenascin-C, but not fibronectin, was deposited around hibernating cardiomyocytes [8], segments of the myocardium that are viable but which exhibit reversible abnormalities in contractile function [10]. Tenascin-C and fibronectin are frequently coexpressed in diseased cardiac tissue as well as in tumor angiogenesis (see below), which suggests that anti-adhesive tenascin- $C$ counteracts the adhesive functions of fibronectin and that both molecules function as accomplices in tissue remodeling (van Obberghen-Schilling et al. 2011).

Tenascin- $\mathrm{C}$ expression is also induced during mouse [11] and rat [12] models of MI, as well as different types of experimental cardiac injury such as myosin-induced myocarditis [13, 14], monocrotaline (MCT)-induced pulmonary hypertension $[15,16]$, cerebral vasospam after aneurismal subarachoic hemorrhage [17], and chronic cardiac rejection [18]. Tenascin-C expression in experimental myocarditis was sequentially documented and found to be up-regulated very early following disease induction, appearing even before cellular infiltration into areas of damaged tissue. It was maintained during active remodeling at the periphery of sites of cell necrosis where it associated with inflammatory foci, but was not found in subsequent scar tissue [13]. Tenascin- $\mathrm{C}$ expression was also followed throughout both acute and chronic models of MI. Murine reperfusion induced MI (RMI) causes an acute inflammatory response followed by rapid remodeling of myocardium and scar formation. MI induced by cryo-coagulation (CMI) is also followed by inflammation, but exhibits a prolonged remodeling phase with delayed scar formation accompanied by persistent macrophage and myofibroblast infiltration. Tenascin-C expression was rapidly induced in RMI and down-regulated towards the end of fibrosis. However, expression was delayed in CMI and maintained throughout the prolonged remodeling [11]. Tenascin-C was also up-regulated in a porcine model of chronic ischemic heart disease, but was not detected in the normal heart or in acute disease [19].

The association of persistent tenascin-C expression with prolonged inflammation and tissue remodeling is also observed in human cardiac pathology. These data are summarized in Table 1. In addition to its re-expression during acute $\mathrm{MI}$, tenascin- $\mathrm{C}$ is found at high levels in diseases such as myocarditis, dilated cardiomyopathy, hibernating myocardium, hypertension, and in end-stage heart failure. Notably, in some of these conditions, tenascin-C expression in heart tissue correlated with disease activity. For example, tenascin- $\mathrm{C}$ was transiently expressed in myocarditis but was not present in normal or healed tissue. It specifically localized to sites of inflammation where tissue levels correlated with the degree of lesion severity [20]. Likewise, in dilated cardiomyopathy, tenascin-C was associated with inflammatory cell infiltration [21] and fibrosis [22] but was not present in healed tissue [21]. Higher tissue tenascin-C was detected in patients with more chronic myocarditis [21].

Circulating tenascin-C levels have also been shown to correlate with poor prognosis and mortality in MI, dilated cardiac myopathy, and heart failure (Table 1). For example, serum tenascin- $\mathrm{C}$ was elevated in patients following acute MI compared to healthy controls, where it peaked 5 days following hospital admission. Follow-up studies showed that tenascin-C levels remained higher in patients that exhibited subsequent left ventricular (LV) remodeling, a major predictor of morbidity and mortality, compared to patients with no remodeling, and indeed was a useful predictor of future adverse cardiac events [23]. Serum tenascin-C levels were also higher in patients with dilated cardiac myopathy compared to healthy individuals, and correlated positively with the severity of heart failure, LV dysfunction and tissue remodeling [24]. Serum tenascin-C in patients with heart failure predicted future cardiac events and correlated with larger LV end-diastolic volume and higher mean pulmonary arterial pressure [25]. Similarly, serum tenascin- $\mathrm{C}$ was increased in patients with idiopathic cardiomyopathy in proportion to the severity of LV dysfunction [26]. Moreover, in patients with chronic kidney disease, a risk factor for developing cardiovascular disease, higher serum tenascin- $\mathrm{C}$ levels predicted associated cardiac pathology [27].

Cardiac resynchronization therapy (CRT) following MI has been shown to improve patient survival. Although the mechanisms by which this occurs are not clear, CRT has been shown to cause reversal of ventricular remodeling. In patients that respond well to CRT, serum levels of tenascin-C were significantly reduced over 6 months [28]. Similarly, while angiotensin II induced hypertension in mice and stimulated tenascin-C expression in fibrotic lesions, treatment with the aldosterone receptor antagonist eplenerone attenuated inflammation and fibrosis and reduced tenascin-C expression [29].

Together, these data suggest that tenascin- $\mathrm{C}$ induction occurs rapidly after cardiac injury where it associates with 
Table 1 Tenascin-C expression in human cardiac pathology

\begin{tabular}{|c|c|c|}
\hline Disease & Tenascin-C expression & Reference \\
\hline Acute MI & $\begin{array}{l}\text { Transient protein expression; serum levels predict major } \\
\text { adverse cardiac events }\end{array}$ & {$[8,23]$} \\
\hline Acute pulmonary thromboembolism & Plasma levels elevated & {$[191]$} \\
\hline Aortic aneurysm & mRNA and protein elevated in vasa vasorum and aortic wall & {$[192,193]$} \\
\hline CRT & Serum levels fall in patients that respond well & {$[28]$} \\
\hline Cerebral vasospasm & Serum levels increase transiently & {$[17]$} \\
\hline Chronic kidney disease & $\begin{array}{l}\text { After cardiac events, large splice isoforms in plasma correlate } \\
\text { with disease progression, predict mortality }\end{array}$ & {$[27]$} \\
\hline Chronic hypertension & Serum levels of B domain isoform elevated & [194] \\
\hline Dilated cardiomyopathy & $\begin{array}{l}\text { Transient protein elevation at sites of inflammation and } \\
\text { fibrosis. Tissue and serum levels correlate with severity of } \\
\text { disease, predict future cardiac events }\end{array}$ & {$[21,22][24,25]$} \\
\hline End-stage heart failure & Plasma levels elevated & [195] \\
\hline Hibernating myocardium & Protein elevated in hibernating myocardial segments & [196] \\
\hline Idiopathic dilated cardiomyopathy & $\begin{array}{l}\text { Serum levels increased in proportion to the severity of LV } \\
\text { dysfunction; tissue protein elevated }\end{array}$ & {$[19,26]$} \\
\hline Myocarditis & $\begin{array}{l}\text { Transient protein elevated in active inflammation; correlates } \\
\text { with severity of lesion }\end{array}$ & {$[20]$} \\
\hline Myxomas & Protein elevated in vascular cellular aggregations & [197] \\
\hline Pulmonary hypertension & Plasma levels elevated & [198] \\
\hline $\begin{array}{l}\text { Valvular heart disease and } \\
\text { coronary artery disease }\end{array}$ & $\begin{array}{l}\text { A1 + protein elevated in areas of interstitial and perivascular } \\
\text { fibrosis; serum levels elevated and protein localizes to } \\
\text { basement membrane of rheumatic valves }\end{array}$ & {$[40,199]$} \\
\hline
\end{tabular}

inflammation and is maintained during tissue remodeling. Its expression is down-regulated and is not present in healed myocardium, but is found both in the tissue and serum of patients with chronic heart disease where levels correlate with prolonged cardiac fibrosis. Circulating tenascin- $\mathrm{C}$ may therefore provide an invaluable diagnostic tool that will be particularly important in cardiac pathologies where disease management can be defined by knowledge of likely poor progression. Treatments that ameliorate cardiac remodeling also reduce tenascin- $\mathrm{C}$ levels, suggesting that it can also be used to monitor tissue repair and improvement in heart function. These data raise a number of intriguing questions such as: what induces tenascin-C expression upon cardiac injury?; what sustains tenascin-C expression in heart disease?; what role does tenascin-C play in cardiac repair and would targeting tenascin- $\mathrm{C}$ expression or function constitute tractable targets for treating cardiovascular inflammation and remodeling?

\section{Regulation of tenascin-C expression in the heart}

As part of an elegantly comprehensive study that examined tenascin-C expression during murine myocarditis, Imanaka-Yoshida and collaborators identified cardiac interstitial fibroblasts as the major source of tenascin-C and demonstrated that the large isoform is produced by these cells [13]. Tenascin-C is also produced by interstitial fibroblasts in fibrotic lesions in angiotensin II induced hypertension [29]. The alternatively spliced domains that are found within the large isoform of tenascin-C contain cleavage sites for matrix metalloproteses (MMPs) [30]. Two recent studies investigated which ECM molecules constitute in vivo substrates for MMP-7 [31] and MMP-9 [32] in mice after experimental MI. Proteomic screening of $\mathrm{LV}$ infarct tissue revealed that tenascin-C fragments increased in wild-type mice after MI but did not appear in MMP-7 and MMP-9 null mice. These data indicate that tenascin- $\mathrm{C}$ is a natural substrate for these proteases during cardiac injury [31, 32]. Deletion of both these proteases improves LV remodeling post MI, implying that MMPmediated degradation of ECM molecules such as tenascin$\mathrm{C}$ may contribute to excess fibrosis during cardiac repair. In addition, serum tenascin-C and plasma MMP-9 levels are both elevated in patients with LV remodeling, and both are reduced in patients that respond well to CRT-mediated reversal of LV fibrosis [28], suggesting that MMP-9 mediated cleavage of tenascin-C may also be relevant in human pathology. Proteolytic cleavage of tenascin- $\mathrm{C}$ has a number of functional consequences; namely modulation of tenascin-C protein levels as well as exposure of cryptic sites concealed within the full-length hexameric molecule. 
The latter can release or remove domains that mediate cell adhesion [33, 34], as well as create or obscure binding sites for other ECM components such as fibronectin [35, 36]. However, the significance of the generation of tenascin- $\mathrm{C}$ fragments in cardiac pathology is not yet clear.

Many factors have been shown to induce tenascin-C expression, including growth factors, inflammatory cytokines, oxidative stress and mechanical stress (reviewed in [37]). Of particular relevance to induction of tenascin-C expression in the heart may be that mediated by mechanical force (reviewed in [38]). Neonatal rat cardiac myocytes subjected to mechanical deformation induced tenascin-C mRNA and protein in an amplitude dependent manner. This activation of tenascin- $\mathrm{C}$ expression involved activation of the transcription factor $\mathrm{NF} \kappa \mathrm{B}$ but occurred independently of PKC and MAPK activation. Mechanically induced tenascin-C was attenuated by antioxidant treatment, and could be independently induced by $\mathrm{H}_{2} \mathrm{O}_{2}$, indicating a role for reactive oxygen species in tenascin- $\mathrm{C}$ expression [39]. These findings suggest that tenascin-C may participate in cardiac remodeling induced by mechanical overload, such as hypertensive heart disease, and that strain-induced reactive oxygen species may potentiate tenascin- $\mathrm{C}$ expression. Most recently, serum from patients with rheumatic valvular disease has been shown to induce tenascin-C mRNA in aortic valve interstitial cells. This induction was inhibited by neutralizing antibodies to $\mathrm{TNF} \alpha$, and to a lesser extent to IFN $\gamma$. Cyclical strain also induced tenascin-C mRNA in these cells in a manner that was dependent on the activation of Rho-kinase but not ERK, p38 MAPK, or PKC. Together, cyclical strain and TNF and IFN $\gamma$ synergistically induced tenascin-C expression in interstitial cells [40]. Finally, in murine cardiac fibroblasts, tenascin-C expression was induced by angiotensin II, TGF $\beta 1$ and PDGF [29], suggesting that a variety of stimuli combine to mediate tenascin- $\mathrm{C}$ expression upon cardiac damage.

\section{The role of tenascin- $C$ in cardiac injury}

The site-specific localization of tenascin- $\mathrm{C}$ during cardiac injury suggests that tenascin- $\mathrm{C}$ may play a role in both the inflammatory and fibrotic phases. Below we highlight the ways in which tenascin- $\mathrm{C}$ has been shown to affect cardiac function during repair and disease.

\section{Cell adhesion}

Tenascin-C has long been known to modulate cell adhesion (reviewed in [2, 41]). It can promote the de-adhesion of cells to the pro-adhesive ECM glycoprotein fibronectin [42, $43]$ and causes down-regulation of focal adhesions [44, 45].
After coronary ligation induced $\mathrm{MI}$ in rats, interstitial fibroblasts expressed tenascin-C mRNA within $24 \mathrm{~h}$, which was down-regulated by 7 days and absent by 14 days. In vitro, tenascin- $C$ increased the number of cardiomyocytes that attached to laminin but inhibited the formation of focal contacts at costameres. These data suggest that synthesis of tenascin-C after MI may serve to reduce the strong adhesion of cardiomyocytes to connective tissue and facilitate tissue reorganization [46]. In support of this, the combined effects of increased tenascin-C mediated deadhesion with a down-regulation of integrin $\alpha 6$ in rat MI may cause cardiomyocyte slippage, leading to adverse ventricular remodeling [16]. Decreased cellular adhesion in the presence of tenascin-C may explain its appearance around hibernating cardiomyocytes post MI [8] where a lack of traction may account for reduced contractile function observed in these areas.

\section{Inflammation}

Transient tenascin-C expression is often associated with acute inflammation, and persistent tenascin- $\mathrm{C}$ with chronic inflammation (reviewed in [1, 47]). In cardiac pathology, tenascin- $\mathrm{C}$ is also associated with inflammatory foci [20, 21] and prolonged macrophage infiltration during chronic murine $\mathrm{MI}$ [11]. Tenascin-C has been shown to exhibit proinflammatory effects mediated by activation of Toll-like receptor 4 in primary human and murine macrophages and fibroblasts [48] and via activation of $\alpha 9$ integrins in murine macrophages [49], although its specific contribution to cardiac inflammation is not known and warrants further investigation.

\section{Tissue remodeling}

The majority of studies examining the role of tenascin-C during cardiac injury have highlighted its role in new tissue deposition or fibrosis. Tenascin-C is expressed during the active tissue remodeling phase of cardiac repair; a process mediated by myofibroblast differentiation and infiltration into the damaged area [3]. A close relationship between tenascin-C and myofibroblasts has been documented in the tumor stroma [50-52] and fibrotic, contractile conditions such as Dupuytren's disease [53]. Persistent tenascin-C expression is also associated with prolonged myofibroblast infiltration during chronic murine MI [11] as well as being a reliable serum marker for adverse ventricular remodeling in a number of human cardiac pathologies (Table 1). In experimental murine myocarditis, tenascin- $\mathrm{C}$ deposition preceded the appearance of myofibroblasts [46], which circumstantially suggests that tenascin-C may induce recruitment or differentiation of these specialized cells. This is supported by studies examining cardiac repair in tenascin-C 
null mice. During MI induced by electrical injury, myocardial repair proceeded normally in mice lacking tenascin-C except that they exhibited delayed infiltration of myofibroblasts into the myocardial interstitium; at sites of necrosis, reduced myofibroblast numbers were detected 1 and 2 days post MI, but levels recovered to resemble those in wild-type mice by 3 days. No defect was observed in cardiac fibroblast proliferation in heart tissue, suggesting that the reduced number of myofibroblasts is not due to tenascin-C promotion of cell proliferation. Indeed, closer in vitro examination of cardiac fibroblasts demonstrated that cells isolated from tenascin- $\mathrm{C}$ null mice exhibited reduced transmigration, lower expression of the myofibroblast differentiation marker $\alpha$-smooth muscle actin and collagen contraction, all defects that could be rescued by the addition of exogenous tenascin- $\mathrm{C}$. These data indicate that tenascin- $\mathrm{C}$ expression during cardiac injury drives myofibroblast migration, differentiation, and contraction. Moreover, the alternatively spliced FNIII repeats and FBG domain were shown to stimulate cardiac fibroblast migration and differentiation, suggesting that these domains are responsible for the observed tenascin-C effects [54]. A second study examined the response of tenascin- $\mathrm{C}$ null mice to $\mathrm{MI}$ induced by permanent coronary ligation. Consistent with data from other models, in wild-type mice tenascin-C mRNA was up-regulated at 1 day, down-regulated by 7 days and not present by 14 days, whereas protein appeared at 1 day, peaked in the developing granulation tissue at 5 days and was subsequently down-regulated over time until 28 days when none was detected. An extremely thorough examination of these mice revealed no histological differences in granulation tissue formation between wild-type and tenascin-C null mice, nor were there any significant differences in rate of animal mortality or infarct size. However, the end-diastolic pressure and dimension, and myocardial stiffness, were lower in tenascin-C null mice. In addition, quantitative analysis of the percentage of interstitial collagen volume in the residual myocardium revealed that matrix deposition was significantly reduced in mice that do not express tenascin-C. This accelerated adverse ventricular remodeling and fibrosis in the myocardium in the presence of tenascin-C suggests that it plays an important role in driving LV remodeling [55].

The molecular mechanisms by which tenascin-C may exert these affects on heart repair are not clear and are likely to be extremely complex. There is evidence that tenascin- $\mathrm{C}$ is closely linked to TGF $\beta$-mediated fibrosis. Tenascin-C expression is induced by TGF $\beta$ in cultured cardiac fibroblasts [20]. In addition, loss of $\operatorname{smad} 3$ resulted in a similar phenotype to that described in the tenascin-C null mice; smad3 null mice exhibit attenuated diastolic function and reduced interstitial fibrosis that was associated with decreased tenascin-C and collagen deposition [56].
These data suggest some interplay between $\operatorname{TGF} \beta$ and tenascin-C signaling pathways. However, in smad 3 null mice, myofibroblast numbers were increased, in contrast to tenascin-C null mice, which exhibited a transient delay in myofibroblast population of injured myocardium. This implies a specific, TGF $\beta$-independent, role for tenascin-C in myofibroblast regulation and a common role in promoting tissue deposition for tenascin-C and TGF $\beta$. Another player in TGF $\beta$ signaling has been linked to tenascin-C expression during cardiac injury in vivo. Loss of $\operatorname{smad} 8$ function in mice results in spontaneous changes in distal pulmonary arteries including medial thickening and smooth muscle hyperplasia that is observed in patients with pulmonary artery hypertension. This is accompanied by increased tenascin-C expression [57].

Tenascin-C expression has also been shown to drive fibrosis in response to other types of tissue injury and in other murine models (reviewed in [1]). In particular, during immune-mediated hepatitis, collagen type I transcription was attenuated in tenascin- $\mathrm{C}$ null mice. These mice also exhibited lower numbers of activated myofibroblasts as well as reduced TGF $\beta$ mRNA [58]. Moreover, tenascin-C null mice exhibit exacerbated renal fibrosis upon snake venominduced glomerulonephritis. Here, the induction of TGF $\beta$ and PDGF was delayed, and levels of collagen and fibronectin deposition were reduced [59]. Together, these data indicate that during tissue repair, tenascin- $\mathrm{C}$ can be induced by TGF $\beta$ but it also induces the expression of TGF $\beta$ itself. This positive feedback loop may mediate the promotion of collagen transcription and deposition. Moreover, tenascin-C may also affect how cells respond to pro-fibrotic growth factors, in addition to controlling their tissue levels. In vitro, mesangial cells isolated from tenascin- $\mathrm{C}$ null mice failed to proliferate in response to $\mathrm{PDGF}$ or $\mathrm{TGF} \beta$, in contrast to wild-type cells [59]. These data suggest a global role for tenascin-C in mediating fibrosis upon tissue injury and raise the question why tenascin-C levels are increased during excessive fibrosis, for example that associated with cardiac pathology. It may be that tenascin-C is persistently induced as a repair mechanism that fails to keep up with increasing damage or that increased tenascin-C itself causes increased damage. These data also highlight the potential of targeting tenascin- $\mathrm{C}$ action in order to reduce aberrant fibrosis. Based on the success of strategies that reduce pro-fibrotic TGF $\beta$ isoforms in ameliorating collagen deposition and scar formation $[60,61]$, this approach may prove extremely valuable.

\section{Tenascin- $\mathrm{C}$ and atherosclerosis}

The most common cause of MI is coronary artery occlusion following the build-up or rupture of atherosclerotic 
plaques. Tenascin-C is expressed during arterial wall injury and accumulating evidence demonstrates that it contributes to both plaque formation and rupture. These data suggest that, in addition to a direct role in mediating cardiac inflammation and fibrosis, tenascin-C may also contribute to one of the major causes of cardiovascular disease.

\section{Tenascin- $\mathrm{C}$ expression in the vasculature}

Arterial expression of tenascin- $\mathrm{C}$ has been examined in experimental models of vascular injury. For example, tenascin-C protein was observed in the intimal layer of the walls of uninjured rat aorta and carotid artery, but was not found in the media. Upon balloon catheter-induced injury, tenascin-C was up-regulated specifically in the neointimal lesion where it was associated with the ECM of proliferating smooth muscle cells (SMC) [62]. Tenascin-C protein and mRNA expression were transiently induced during murine neointimal hyperplasia caused by abdominal aortotomy. After aortic suture, tenascin-C was observed by 7 days in the media and periadventitia around the suture line, staining increased by 14 days in the neointima and media but was not detected by 28 days [63]. Grafting of abdominal arteries to carotid arteries also causes neointimal hyperplasia in mice. Here, tenascin-C expression was transiently induced in the media and intima of both the donor and recipient vessel 14 days after transplantation [64]. Tenascin-C expression was also induced in atherosclerotic plaques formed in the arteries of apoE null mice on a high-cholesterol diet [65]. Interestingly, in rat models of MCT-induced hypertension, tenascin-C was expressed in the central and peripheral pulmonary arteries in the adult, but not in infant vessels. The latter tissues spontaneously repair vascular lesions where adult tissues do not [66]. These data suggest that, as with many other types of tissue injury, transient tenascin- $\mathrm{C}$ expression is induced upon vascular damage and is down-regulated and cleared from the tissue after repair is complete. They also imply that lack of tenascin-C may be associated with improved vessel repair outcomes.

Persistent expression of tenascin- $\mathrm{C}$ is associated with human arterial pathology, the best-studied example of which is atherosclerosis. Wallner and collaborators first demonstrated tenascin-C expression in human atherosclerotic plaques where levels appeared to increase with plaque progression. Minimal staining was observed in early fibrous plaques, but high levels were found in lipid rich plaques, both in and around the lipid core. In two ruptured plaques, strong tenascin-C staining was localized to the area of rupture. Tenascin- $\mathrm{C}$ specifically localized to areas of macrophage accumulation in plaques that were heavily infiltrated with immune cells, but was absent from the
SMC-populated adventitial and medial layers [67]. Tenascin-C expression also correlated with ruptured plaques in patients with acute coronary syndromes. Tenascin-C was found in all plaques obtained from patients with stable angina or acute coronary syndromes. However, quantification of the area of tenascin-C immunoreactivity revealed that staining was highest in areas adjacent to thrombus formation and in plaques with inflammatory infiltrate and intra plaque hemorrhage [68]. Differential expression of tenascin- $\mathrm{C}$ during atherosclerosis was confirmed by analysis of the gene expression profile of human aortas with varying degrees of atherosclerotic disease by microarray [69]. In fact, most studies have compared tenascin-C expression in arteries with different stages of disease, likely due to tissue availability. However, in some studies, human mammary artery was used as a control and tenascin- $\mathrm{C}$ expression was found to be absent [67]. This lack of tenascin-C expression in mammary arteries was confirmed by Qin and collaborators. Using subtractive hybridization, they examined gene expression in porcine arteries that are prone to developing atherosclerosis (coronary) and those that are athero-resistant (mammary). Tenascin-C was among those genes that were preferentially detected in normal coronary arteries, along with lipid retention, growth and inflammation genes [70]. These data suggest that basal levels of tenascin-C are present in normal athero-prone arteries. Most adult arteries will likely have suffered some arterial insult over time, so it may be hard to define a truly 'normal' level of tenascin-C expression in coronary arteries without examining fetal or juvenile tissue.

Increased tenascin-C expression in coronary artery atherosclerotic lesions was found to be associated with increased TGF $\beta$, higher numbers of macrophages and TUNEL-positive cells in diabetic patients that succumb to acute MI [71]. The accumulation and subsequent oxidation of LDL in the arterial wall is key to the development of atherosclerosis. The release of aldehydes from this reaction has been shown to modify ECM components including fibronectin and tenascin-C: autoantibodies to aldehydeconjugated fibronectin and tenascin- $\mathrm{C}$ were found in the plasma from atherosclerotic patients [72]. A recent study also examined the prevalence of 35 tenascin-C SNPs in three independent cohorts of patients with atherosclerosis and cardiovascular disease $(n=205, n=1,325, n=879$, respectively). Three SNPS were found to be in high linkage disequilibrium and associated with high risk of atherosclerosis in all data sets. Of these, one coding SNP was located in TNfnIII8, which in combined analyses was statistically significant $[p=5 \times 10 \quad(-6)]$. Although synonymous, it was proposed that this may potentially affect tenascin-C function by affecting mRNA structure and stability or splicing efficiency, even in the absence of any amino acid sequence alteration. Interestingly, this SNP 
association was predominantly observed in late-stage plaques [73], consistent with reports that tenascin-C expression peaks during late-stage disease and plaque rupture. Additional genetic evidence reveals that the tenascin-C gene is located within a quantitative trait locus (Ath8) that influences the difference in susceptibility to atherosclerosis between the NZB/BINJ and SM/J mouse strains [74].

In addition to atherosclerosis, tenascin- $\mathrm{C}$ expression has also been reported in the adventitia media of human vein grafted arteries but not in normal veins [75] and transient induction observed in arterial walls followed over time after coronary artery bypass grafting-induced stenosis [76]. Together, this body of evidence suggests that tenascin-C expression is transiently induced upon arterial injury, but is persistently expressed during arterial disease increasing towards the advanced stages of atherosclerotic plaque development, where expression correlates with inflammation and plaque rupture.

\section{The role of tenascin- $C$ in atherosclerosis}

Upon arterial injury, for example that caused by a high-fat diet, changes in the endothelium allow immune cell adhesion and transmigration into the vessel wall intima. Infiltrating cells such as macrophages and $\mathrm{T}$ lymphocytes activate the proliferation of SMC in the adventitia, which migrate into the developing intimal plaque site. Together with invading myofibroblasts, SMC mediate excessive ECM deposition that propagates plaque growth. The expansion of the plaque increasingly occludes vessel blood flow, and as it matures and calcifies it can rupture enabling thrombosis to occur $[77,78]$. Below we highlight how tenascin- $\mathrm{C}$ has been implicated in the development and progression of atherosclerosis by taking part in a number of these different processes.

\section{The source of tenascin-C during vascular injury}

A number of cell types from distinct lineages are implicated in producing tenascin-C during arterial injury. Based on the co-localization of tenascin-C protein and mRNA with infiltrated macrophages in human atherosclerotic plaque sections, Wallner and collaborators examined tenascin- $\mathrm{C}$ expression in this cell type. A small form of tenascin-C (7-kb transcript, 220-kDa protein) was constitutively expressed by human monocyte-derived macrophages [67]. Consistent with data that identify macrophages as a source of tenascin- $\mathrm{C}$, we also demonstrated that tenascin- $\mathrm{C}$ is produced by primary human macrophages [79]. It was also demonstrated by in situ hybridization during balloon-induced rat and porcine arterial injury, that tenascin- $\mathrm{C}$ was expressed 3 days after injury by adventitial myofibroblasts [80]. The association of tenascin-C with this cell type has been discussed in previous sections of this review.

In rat models of MCT induced hypertension, tenascin-C expression correlated with proliferating SMC [66]. Hedin also proposed the source of tenascin-C during experimental arterial damage to be SMC based on its association with proliferating $\alpha$-smooth muscle actin-rich cells during balloon catheter injury. Primary rat aortic SMC have been shown to assemble tenascin-C fibrils in culture [62] and tenascin-C expression in cultured rat aortic SMC can be induced in response to a number of different stimuli. PDGF [67] and angiotensin II [81] both induce a large and small form of the protein (7- and 8.4-kb transcript, 220- and $280-\mathrm{kDa}$ protein). SMC isolated from newborn rat aortas specifically express a tenascin-C isoform containing the alternatively spliced domains $\mathrm{A} 1$ and $\mathrm{A} 2$. This isoform is upregulated by PDGF but is down-regulated in adult rat aortic SMC, where it re-appears only after carotid injury [82]. Mechanical strain also induced tenascin-C expression in SMC. Microarray analysis of primary human vascular SMC exposed to biphasic axial strain revealed that only three transcripts out of 5,000 assessed were induced $>2.5$ fold: cyclooxygenase-1, tenascin-C, and plasminogen activator inhibitor-1. These data suggest that a highly specific response of this cell type to the strain [83]. Pulmonary blood flow also regulates tenascin-C expression. Ligation of porcine pulmonary arteries increased tenascin$\mathrm{C}$ expression, suggesting that the hemodynamic changes are key in modulating arterial ECM remodeling [84].

Other studies showed that tenascin-C expression is regulated in rat aortic SMC by the structural state of the cell environment. Culturing cells on native fibrillar type I collagen suppressed tenascin-C expression, whereas MMPproteolyzed or monomeric/denatured collagen induced transcription. These differential responses are mediated by the ligation of distinct receptors by each type of ECM; $\alpha \mathrm{v} \beta 3$ integrin-mediated MAPK activation was able to induce tenascin-C expression by digested matrices but ligation of $\alpha 2 \beta 1$ integrins by intact collagen did not [85]. Tenascin-C up-regulation in hypertensive arteries correlated with the expression of the homeobox transcription factors Prx1 and Prx2. In rat aortic SMC cultured on denatured collagen, induction of Prx 1 and Prx 2 was high compared to that in cells cultured on native type I collagen. Over-expression of Prx1 significantly induced SMC growth as well as tenascin-C expression, suggesting that regulation of tenascin- $\mathrm{C}$ expression by the physical organization of the ECM is mediated by Prx family members [86].

Coincident with increased tenascin-C expression on denatured collagen, SMC exhibit an altered morphology, 
with a well-defined network of actin stress fibers. Enforced geometric changes in cell shape were found to dictate tenascin- $\mathrm{C}$ expression; as cells rounded, tenascin- $\mathrm{C}$ expression dropped. RhoA- and ROCK-mediated cytoskeletal architecture formation was shown to be responsible for creating a cell morphology that is permissive for ERK-dependent tenascin-C expression in cultured SMC. Moreover, ROCK inhibition suppressed the expression of tenascin-C by SMC in hypertensive rat pulmonary arteries [87]. These data suggest that RhoA and ROCK, factors which also regulate vasoconstriction in pulmonary hypertension, may couple vessel contraction with ECM remodeling and cellular architecture.

\section{Tenascin-C and smooth muscle cell function}

The detailed examination of tenascin-C expression in SMC has been paralleled by investigation into the potential functional relevance of its up-regulation in this cell type, and the evidence points predominantly to a role in mediating neointimal hyperplasia.

SMC migration and proliferation are both key features in plaque development. Tenascin-C expression during experimental arterial injury in vivo was associated with a change in SMC phenotype from a non-proliferative phenotype to a migratory, synthetic state [62]. Cell migration relies on dynamic adhesion and de-adhesion to the underlying substratum. Both SMC derived from adult and newborn rats adhered to a tenascin- $\mathrm{C}$ substrate, although newborn cell adhesion was threefold greater than that of adult cells. SMC did not spread on tenascin-C in contrast to cells plated on fibronectin. This interaction was RGDdependent and shown to be mediated by 30 amino acids within the FBG domain of tenascin-C [88]. This region was later shown to bind to $\alpha \mathrm{v} \beta 3$ integrins [89]. In addition, tenascin- $\mathrm{C}$ inhibited the adhesion of human and rat SMC to fibronectin [90]. These data collectively suggest that tenascin- $\mathrm{C}$ may modulate or destabilize SMC attachment to the ECM during migration. Tenascin- $\mathrm{C}$ isoforms containing the A1A2 domains also promoted SMC chemotaxis in vitro [82], suggesting that the splice variants that are specifically up-regulated by SMC during arterial injury may also directly attract further SMC to the injury site.

A series of papers from Jones and collaborators examined the role of tenascin- $\mathrm{C}$ in modulating $\mathrm{SMC}$ response to different growth factors. Culturing rat SMC on tenascin-C enhanced cellular growth upon stimulation with bFGF and was essential for proliferation in response to EGF [66]. In lung biopsy tissue from patients with congenital heart defects and pulmonary hypertension, the distribution of tenascin-C, EGF, and proliferating cell nuclear antigen strongly overlapped in obstructive lesions [91] circumstantially linking tenascin-C and EGF-mediated cell growth in vivo. Tenascin-C ligation of $\alpha \mathrm{v} \beta 3$ integrins was shown to mediate focal adhesion formation that contained clusters of activated EGF receptor molecules, and crosslinking $\alpha \mathrm{v} \beta 3$ integrins was sufficient to replicate the effect on plating cells on tenascin-C substrates [92]. Similarly, most recently, rat SMC cell lines plated on a tenascin-C substrate exhibited enhanced proliferation and migration in response to PDGF. Cells grown on tenascin-C exhibited increased phosphorylation of PDGF receptor beta and clustering of $\alpha \mathrm{v}$ integrins and activated FAK and src at focal adhesions [93]. Together, these data indicate that crosstalk between integrin and growth factor receptors can amplify cell proliferation and migration upon activation with their cognate ligands; growth factors such as PDGF or EGF and tenascin-C.

SMC apoptosis is a key feature of the later stages of atherosclerotic plaque development [94]. Despite an association with tenascin-C and SMC proliferation described above, tenascin- $\mathrm{C}$ also co-localized to TUNEL-positive cells in human atherosclerotic lesions [71]. A later study showed that cultured human SMC can degrade full-length tenascin-C substrates to yield fragments that were detected with an antibody against the EGF-L repeats. EGF-L-containing fragments were also detected in human endarterectomy specimens. Recombinant EGF-L induced apoptosis in SMC via activation of caspase-3, where intact tenascin-C and its other constituent domains did not affect cell viability [95]. These data suggest that while intact tenascin-C may drive SMC survival in atherosclerosis, towards the end stages of plaque formation, tenascin-C degradation releases cryptic fragments that mediate SMC apoptosis.

\section{Modulating tenascin- $\mathrm{C}$ expression and function during vascular disease}

A number of studies examining vascular injury and disease in mice with targeted deletions in tenascin- $\mathrm{C}$ or the effect of ablating tenascin-C expression have confirmed an important role for this ECM glycoprotein in mediating neointimal hyperplasia by stimulating SMC proliferation and migration, as well as enhancing ECM deposition.

Tenascin- $\mathrm{C}$ null mice are refractory to experimental neointimal hyperplasia induced by aortotomy. Quantitatively less hyperplasia was observed in these animals compared to wild-type mice, and this was accompanied by a lower proliferating cell nuclear antigen index and less proteoglycan deposition [63]. Grafting aortic segments from tenascin-C null mice into null recipients significantly reduced neointimal hyperplasia and SMC proliferation compared to wild-type grafting [64]. Similarly, in a distal 
anastomotic stricture model of free artery graft stenosis, tenascin- $\mathrm{C}$ expression was induced over time in the media and neointima of the graft body in rat abdominal aortas. Local application of the cAMP phosphodiesterase inhibitor cilostazol around the graft was found to reduce neointimal hyperplasia and cell proliferation as well as to suppress tenascin-C expression [96].

Organ cultures of hypertrophied rat pulmonary arteries progressively thicken and exhibit cellular proliferation and ECM accumulation, providing a good ex vivo model system with which to assess neointimal hyperplasia. In these cultures, antisense inhibition of tenascin-C expression arrested arterial thickening by inducing SMC apoptosis. However, cultures with silenced tenascin-C did not completely regress as expansion of an SMC population expressing an alternative $\alpha \mathrm{v} \beta 3$ survival ligand, osteopontin, compensates for loss of tenascin-C [97]. These data suggest that inhibition of tenascin- $\mathrm{C}$, in combination with other inducers of SMC survival, may represent a promising strategy for the prevention of neointimal thickening during atherosclerosis and bypass grafting.

\section{Tenascin- $\mathrm{C}$ and thrombosis}

In thrombosis, platelet-mediated formation of a fibrin-rich blood clot is a key response to wound healing, but also contributes to luminal narrowing of the arteries during atherosclerosis. It occurs in arteries with advanced disease that have significantly narrowed lumens or altered blood flow and causes further artery blockage. It is hypothesized that these arterial walls become rich in platelet adhesive substrates. Tenascin-C was recently shown to support the adhesion of platelets in vitro under both static and shear flow conditions. This interaction was mediated primarily by $\alpha 2 \beta 1$ integrins in static culture, but additionally required the GPIb-IX complex, and to a lesser extent $\alpha \operatorname{IIb} \beta 3$ integrins, under flow. Von Willebrand factor (vWF), a known ligand for GPIb-IX, was shown to be required for GPIb-IX binding to tenascin- $\mathrm{C}$ and a direct interaction between purified vWF and tenascin-C was demonstrated [98]. These data identify a number of novel binding partners for tenascin-C. Moreover, the adhesion of platelets to tenascin-C resulted in their activation [98], suggesting it may provide an ECM that is permissive for thrombosis. Given the high levels of expression of both tenascin-C and vWF in atherosclerotic plaques, platelet activation by these molecules may also promote thrombus formation during late atherosclerosis. Tenascin-C expression in advanced plaques lies close to areas of plaque rupture and thus may be exposed to circulating platelets. The success of antithrombotic drugs such as $\alpha \operatorname{IIb} \beta 3$ blockers has been tempered by side-effects that include increased risk of bleeding. Tenascin- $\mathrm{C}$ null mice exhibit normal hemostasis [98], suggesting that a strategy targeting tenascin-C-mediated thrombosis may enable uncoupling of hemostasis from thrombosis to prevent arterial narrowing with fewer side-effects.

Another way in which tenascin-C might contribute to fibrin-mediated luminal occlusion is by triggering fibrin accumulation via down-regulation of tissue plasminogen activator. In comparing the gene-expression profiles of embryonic fibroblasts isolated from wild-type or tenascin-C null mice, the group of Chiquet-Ehrismann identified tissue plasminogen activator as the most consistently overexpressed gene in tenascin-C-deficient cells. In the absence of tenascin-C, cellular digestion of a fibrin-agarose matrix was enhanced. Moreover, during lung inflammation and fibrosis induced by bleomycin, tenascin- $\mathrm{C}$ accumulated in areas of fibrin deposition, as well as in the lungs of asthmatic patients and in lung tumors and head and neck carcinomas [99]. This is consistent with reports of tenascin$\mathrm{C}$ in fibrin-rich deposits in synovium from RA patients [79]. These data suggest that tenascin-C acts as a regulator of fibrin deposition by negative transcriptional control of tissue plasminogen activator, and this enables fibrin accumulation during arterial injury.

\section{Tenascin-C-MMP feedback loops in vascular disease}

Throughout the vascular pathology literature there is a recurring link between tenascin-C and MMPs. Several of these proteases are thought to be key players in mediating plaque rupture [99]. Increasing tenascin-C expression also correlates with increasing plaque instability, and this together with the fact that macrophages are one of the major sources of tenascin- $\mathrm{C}$ in the atherosclerotic plaque prompted Wallner and collaborators to examine MMP synthesis by RAW macrophages in response to tenascin-C. These cell lines, when cultured on a tenascin-C substrate for $24 \mathrm{~h}$, demonstrated increased MMP9 activity [67]. This group also showed that tenascin-C stimulates MMP-2 expression and gelatinolytic activity in cultured SMC [95].

MMPs have also been linked to the induction of tenascin$\mathrm{C}$ expression. The pan-MMP inhibitor GM6001 suppressed tenascin-C expression in rat SMC cultured on native fibrillar type I collagen, although induction of tenascin-C expression by cells on denatured collagen was MMP-independent. Tenascin-C and MMP-2 levels were high in cells seeded in attached collagen gels, but in floating collagen gels, tenascin-C expression was suppressed, concomitant with suppressed MMP-2 levels [92]. Likewise, tenascin-C and MMP expression was linked in artery organ cultures. Normal porcine pulmonary arteries embedded in attached collagen gels exhibited increased activity of MMP-2 and MMP-9 as well as tenascin-C. In contrast, arteries cultured in floating 
gels showed reduced MMP activity and tenascin-C expression. Hypertrophic arteries exhibited the same trend of protein expression in floating and attached gels, albeit with higher overall levels of MMP-2 and tenascin-C. Culture of arteries in floating gels was accompanied by cell apoptosis and regression of the thickened media of hypertropic vessels [100]. In further studies, treatment of hypertrophied rat pulmonary studies with serine elastase inhibitors or GM6001 induced regression, an effect that was associated with reduced tenascin-C expression [97]. Human calcific aortic stenosis cusps exhibit a co-localization of tenascin- $\mathrm{C}$ and MMP-2 deposition and MMP-2 activity, where deposition of these proteins appears to be linked to areas of calcification [101]. Tenascin-C, MMP-2 and MMP-9 expression also coincide in subdermal elastin implants that undergo calcification in vivo. The MMP inhibitor BB-1101, when injected systemically or locally into the implant, was extremely effective in suppressing tenascin-C expression. Elastin calcification was also reduced after treatment with BB-1101 [102]. These data suggest that targeting MMP-mediated tenascin-C induction may provide a useful point of intervention in vascular disease.

It is not clear how MMPs induce tenascin- $\mathrm{C}$ expression, or vice versa, during vessel injury in vivo. Tenascin-C induction may result from direct stimulation of gene expression by MMPs or indirectly via MMP regulation of the extracellular environment; as described above, MMP digested type I collagen is effective at stimulating tenascin$\mathrm{C}$ transcription [85]. Finally, MMPs also cause fragmentation of tenascin-C [30]. Specifically, SMC produce pro-apoptotic tenascin- $\mathrm{C}$ fragments the generation of which could be prevented by inhibition of MMP activity with the pan-inhibitor GM6001 [95]. Thus MMPs can mediate post-translational control over tenascin-C activity, in addition to regulating the transcription of this gene, which in turn may induce further MMP expression and activation. Thus, a positive feed-forward loop may result that drives plaque progression, destabilization, and eventual rupture.

\section{Tenascin-C in stem cell biology}

In addition to the advances in our understanding of tenascin- $\mathrm{C}$ in cardiac and arterial biology and pathology, investigations into the role of tenascin- $\mathrm{C}$ in stem cell biology are also gathering pace, particularly in the central nervous system (CNS) and in the context of tumorigenesis.

\section{Tenascin- $\mathrm{C}$ in neural stem cells}

Studies have reported several CNS-specific abnormalities in the tenascin-C null animals [103, 104]. Phenotypic differences were reported, depending on the genetic background of the mouse strains used for analyses: while the migration of oligodendrocyte progenitors (OP) from mice which do not express tenascin- $\mathrm{C}$ was always enhanced, when compared to their heterozygous counterparts, in C57BL6 J/CBA mice. However, this was not always observed in strain 129 mice [103]. Tenascin-C was also shown to regulate a mitogenic response in OP, a role dependent on integrin $\alpha v \beta 3$ and PDGF signaling [103]. Moreover, significant reductions in the number of radial glial cells ( $\mathrm{RC} 2+$ cells, a subset of stem cells in the embryonic CNS) were observed throughout the development of the CNS at E13.5, E18.5, and immediately upon birth at P0 [104]. Neural stem cells (NSC) were isolated form murine CNS and grown as neurospheres in vitro. NSC neurospheres from tenascin-C null mice derived from E10.5 rostral telencephalic vesicles were FGF2 responsive but unresponsive to EGF [104]. When neurospheres were established from newborn animals (P0), tenascin-C null cells were more numerous but smaller than the ones derived from wild-type animals. In addition, these tenascin-C null neurospheres were less responsive to FGF2, but responded similarly to EGF stimulation. Differentiation assays indicated that the three lineages (neurons, astrocytes, and oligodendrocytes) could be formed from tenascin-C null NSCs in vitro. A few phenotypical differences between cells derived from wild-type or null mice were however observed and concerned the formation of longer cellular processes of oligodendrocytes and an increased number of neurons. The addition of exogenous tenascin- $\mathrm{C}$ to the culture medium specifically reverted the enhanced neuronal differentiation of tenascin- $C$ null cells. Altogether, this shows that tenascin- $\mathrm{C}$ is dispensable for the maintenance of NSC, but is still implicated in the control of NSC fate choices (self-renewal/proliferation and differentiation) and the migration and differentiation of their progeny.

More recently, in vitro differentiation of embryonic stem cells (ESC) to NSC using retinoic acid followed by differentiation into neurons and astrocytes revealed that tenascin- $\mathrm{C}$ is induced together with proteoglycans, glypican-1, and RPTP $\zeta / \beta$ (a receptor for tenascin-C) in both NSC and differentiated cells [105]. This suggests that when in vitro models of NSC are used, tenascin-C seems to play important roles in regulating mechanisms controlling NSC self-renewal and differentiation.

At the molecular level, recent progress has also been made and sheds new light on the complexity of the downstream mechanisms that tenascin-C regulates in NSC. Von Holst and coworkers found that 20 different tenascin$\mathrm{C}$ isoforms generated by alternative splicing are expressed in neurospheres in vitro [106]. Furthermore, using proteomics-based approaches, it was shown that tenascin- $\mathrm{C}$ is 
post-translationally modified by the HNK-1 modification in NSC [107]. The HNK-1 epitope (Human Natural Killer-1, aka CD57) consists in a trisaccharide and a terminal glucuronyl residue and was mostly found on the largest isoforms of tenascin-C [107]. From a functional perspective, the HNK-1 post-translational modification promotes tenascin-C-dependent NSC proliferation via the EGFR and the Ras/MAPK (ERK1/2) pathways [107].

A novel function of tenascin-C was also uncovered by von Holst et al. [108], who showed that tenascin-C can reduce the expression of Sam68, a member of the STAR protein family. Sam68 is a well-known signaling adaptor of various receptors [109] and a RNA-binding molecule that regulates different steps of mRNA processing, depending on the cellular context [110]. Conversely, upon its over expression, Sam68 can also modulate tenascin-C mRNA splicing, which could represent a signaling feedback mechanism by inducing the largest isoforms of tenascin-C mRNAs that contained 5-6 type III FN repeats [108]. Mechanistically, tenascin-C inhibits OP differentiation and is able to bind contactin and Fyn, localized at oligodendrocyte membrane rafts [111]. Hereby, tenascin-C leads to reduced Akt phosphorylation and reduced expression of both myelin basic protein and Sam68 in a PI3kinase pathway-dependent manner [111]. These studies provide a new mechanism by which tenascin-C, via Sam68, may control signal integration, cellular adaptation, and decisionmaking by NSC and their progeny. Therefore, the further characterization of the roles and the targets downstream of tenascin-C and Sam68 on a genome-wide scale in relevant cellular contexts represent exciting and novel opportunities potentially leading to broader applications.

\section{Tenascin- $C$ in tumor-derived endothelial cells}

It was recently demonstrated that glioblastoma (GBM) stem cells can transdifferentiate into microvascular endothelial cells and form functional vessels within GBM [112, 113]. While it is currently unknown whether these cells express tenascin-C, it was reported that peri-vascular progenitors and tumor-derived endothelial cells (TEC) can also be observed in neuroblastoma (NB) patient samples and cell lines [114]. These peri-vascular progenitors and TEC specifically express both Oct-4 (a stem cell marker and master regulator of pluripotency in ESC) and tenascinC [114]. Importantly, the tumor origin of the Oct $4+$ cells was assessed by showing that $N-m y c$ gene amplification, a well-known genetic aberration and hallmark of NB tumor cells, is detected in the genome of these cells. In addition, the authors sorted tenascin- $\mathrm{C}+$ and-NB cells from cell lines and assessed their differential capacities. In vitro, tenascin-C $+\mathrm{NB}$ cells had the capability of growing as neurospheres while tenascin-C- cells could not [114]. In vivo upon orthotopic xenografting in nude mice, cells with both immunophenotypes formed tumors; however, the tumors derived from tenascin-C + cells had a significantly larger volume and harbored TEC and tumor-derived vessels [114]. No tumor-derived vessel was indeed observed in the (smaller) tumors derived from the tenascin-C- NB cells [114]. These latter observations suggest that tenascin-C may not be important to confer tumor-initiating properties to NB cells but rather is crucial to promote tumor growth and progression by sustaining aberrant and tumor cellderived angiogenesis.

Altogether, these studies support the notion that tenascin-C may play key roles in promoting brain tumor progression by stimulating angiogenesis through the establishment of tumor cell-derived vessels. This property of tumor cells to transdifferentiate into endothelial cells could represent a specificity of gliomas and neuroblastomas, and hereby represent a molecular reminiscence of their developmental original neural phenotype. NSC themselves are indeed able to transdifferentiate into endothelial cells, on the contrary to most epithelial adult tissue-specific stem cells for example. It will be therefore of interest to further characterize the generality of this recently uncovered capacity of tumor cells, the functionality of tumor-derived blood vessels, and the implication of tenascin- $\mathrm{C}$ in the control of this transdifferentiation process.

\section{Tenascin- $C$ in melanoma cancer stem cells}

In melanoma cell lines, it was recently shown that tenascin$\mathrm{C}$ expression is induced when cells are grown as spheres in vitro and that tenascin- $\mathrm{C}$ knock down diminished cell proliferation specifically when the cells were grown as spheres [115]. In vitro culture of tumor cells as spheres is known to enrich for and propagate cells with tumor-initiating properties. Upon subcutaneous grafting of these cells into immuno-compromised NOD/SCID mice, tenascin-C knock down melanoma cells were not impaired in primary tumor formation and growth. However, upon intravenous injections of the same cells, lung colonization and metastasis formation were severely impaired for tenascin-C knock down melanoma cells [115]. Moreover, tenascin-C seems to be important in maintaining the side population (SP) fraction of melanoma cells in the spheres in vitro: tenascin-C knock down indeed diminished the fraction of SP cells, which represent a subpopulation of cancer cells that efficiently efflux drugs, via the up-regulation of $\mathrm{ABC}$ transporters, ABCB5 in this case [115]. Hereby, tenascin-C knock down potentiated the action of doxorubicin in inducing melanoma cell apoptosis, while the addition of 
tenascin-C to melanoma spheres supported their resistance to the drug [115].

Overall, these different studies suggest various roles for tenascin- $\mathrm{C}$ in controlling processes crucial to stem cell homeostasis and mobilization in various physiological and tumor contexts. It will therefore be of further interest to study the contribution of tenascin-C in stem cells, progenitors, and cancer stem cell contexts and in particular determine through which signaling activities tenascin-C is implicated. Such studies will with no doubt pave the way towards novel translational opportunities for patients in regenerative and cancer medicines.

\section{Tenascin-C expression in cancers: prognostic value and correlation to clinical outcome}

As mentioned above, tenascin-C expression is tightly regulated during the adult lifespan and is mostly restricted to physiological conditions requiring active remodeling of tissue such as wound healing and inflammation [1, 47]. Its increased expression has been reported in the stromal compartment of cancers from various origins and was recently reviewed [1]. Here we present recent data further illustrating that tenascin-C expression represents a predictive value for local recurrence and metastatic dissemination of breast cancers, GBM, and other cancer types. Significant advances have also been made to characterize the spliced isoforms of the molecule present in specific cancer tissues [114], their histological localization and mechanistic signals controlling their expression [37], and role in cancer cell invasion [114].

\section{Tenascin- $C$ in breast cancers}

Tenascin-C was early described as a stromal marker associated with malignant behavior of breast cancers [116]. Large spliced variants of the molecule containing exons 16 or 14/16 (coding for FNIII repeats A4 and AD2, respectively) seemed correlated to invasion [117] and exon 15 (encoding FNIII repeat B) expressing tenascin-C was detected at the invasive front of breast ductal carcinoma in situ [118]. More recently, TNC-16 and TNC-14/16 were shown to be highly expressed, and to upregulate the expression of the matrix metalloproteinase 13 in different invasive breast carcinoma cell lines, thereby stimulating their invasive potential [119]. Expression of tenascin-C isoforms in breast cancers can be elicited by various stimuli including low $\mathrm{pH}$ and TGF- $\beta$. Moreover, in situ hybridization revealed that different splice variants of tenascin- $\mathrm{C}$ can coexist in the same tumor tissue, suggesting that precise local microenvironmental cues determine the spatial confinement of specific isoforms that may functionally differ [114]. The same authors correlated expression of $\mathrm{AD} 1$ domain harboring tenascin- $\mathrm{C}$ with estrogen negative grade 3 breast carcinomas in young women [120]. Spliced isoforms of tenascin- $\mathrm{C}$ might therefore be associated with specific pathological contexts and may determine clinical outcome.

Transcriptomic analysis led to the incorporation of tenascin-C among a list of genes that contributes to breast cancer metastagenicity to the lung [121]. Tenascin-C was confirmed to be part of a gene signature relevant to lung metastasis through tumor xenograft of MDA-MB-231 cells derivatives presenting distinct invasive properties in nude mice. Moreover, miRNA profiling revealed that tenascin-C and Sox4 were down-regulated targets of miR335 and correlated with aggressive behavior and propensity of breast cancer cells to colonize the lung [122]. Interestingly, tenascin-C was also reported to be a direct target of Sox 4 transcriptional regulation in prostate cancer cell lines, suggesting an amplification loop of its expression that could also be associated to invasive abilities of other cancer models [123]. A tumorigenic function of tenascin-C was also evoked in a three-dimensional acinar culture model of non malignant MCF-10A cells externally delineated by a basement membrane [124]. When cultured in the presence of tenascin-C, MCF-10A acini deposited a loosely organized basement membrane and presented an elevated level of c-Met (HGF/scatter factor receptor) expression inducing luminal filling and cell proliferation, which is reminiscent of early steps in breast cancer. This effect was reversed by functional blocking of the proto-oncogene, and suggested a new tumorigenesis supporting function of tenascin- $\mathrm{C}$ in breast cancer. Moreover, tenascin-C expression in breast cancer tissue could have consequences to anti-cancer treatment responsiveness, as illustrated by a recent study that correlated tenascin-C expression to shorter survival of tamoxifen-treated patients with estrogen-positive breast cancer [125].

\section{Tenascin-C in brain tumors}

GBM are among the most common malignant brain tumors, and are characterized by genomic instability, intense vascularization, and unpredictable clinical behavior. Because of their adaptivity to anti-cancer drug treatment, GBM present a poor prognosis and a limited number of clinical targets have been referenced so far. Tenascin-C is highly expressed in GBM and has been associated with local invasion, shorter disease-free survival [126], and worse overall survival prognosis (Fig. 2). A study on a large set of gliomas revealed that strong perivascular staining of tenascin-C is associated with tumor 


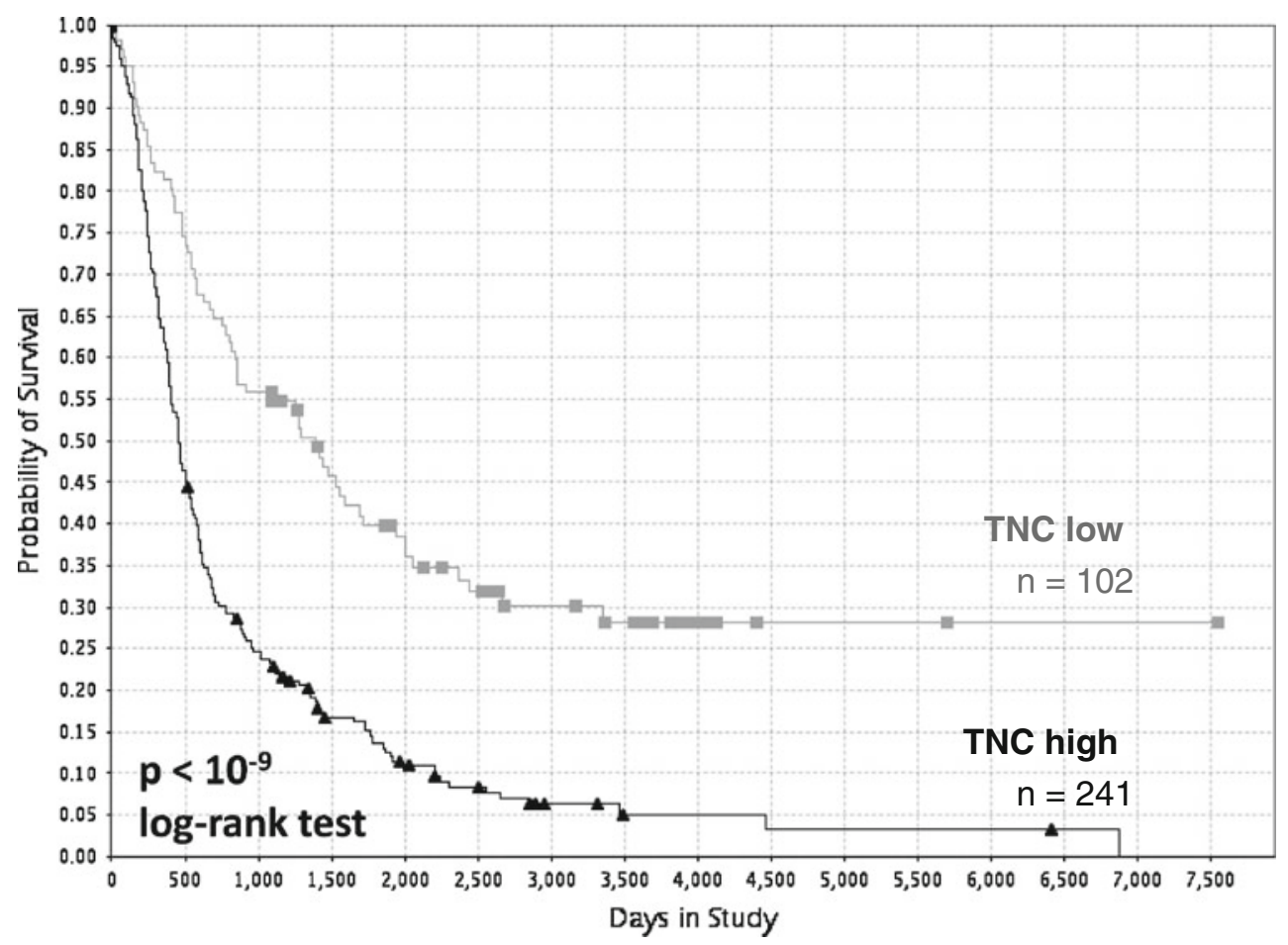

Fig. 2 High Tenascin-C expression correlates with poor outcome for glioma patients. Publicly available gene expression profiling data [190] were used to stratify glioma patients according to the level of over-expression of $T N C$ in these tumors (compared to normal brain

malignancy and functional blocking of tenascin-C in glioma cell lines inhibited proliferation and migration, suggesting that tenascin- $\mathrm{C}$ could constitute a reliable marker and a potential therapeutic target [127]. Tenascin-C expression was recently included in a list of nine genes that had predictive value in GBM malignancy and was associated with mesenchymal differentiation of GBM cells and angiogenesis [128]. An elevated expression of tenascin-C was also detected in oligodendrocytomas, astrocytomas in addition to GBM tissues as compared to healthy brain samples [129].

A recent study showed that tenascin-C knock down in the human LN229 GBM cell line had no significant in vitro effect on cell proliferation but abolished cell migration by promoting focal adhesion disassembly signals [130]. Upon orthotopic xenografting, control tumors presented frequent cell clusters detached from the principal tumor mass that were surrounded by tenascin-C. In contrast, tenascin-C knocked down tumors had a decreased number of glioma cell clusters infiltrating adjacent brain parenchyma. Through MRI of patients with GBM, the authors correlated the volume of peritumoral reactive parenchyma, which can result either from focal brain edema or structural modification following GBM infiltration, to high tenascin-C mRNA levels measured in surgical explants [130]. Tenascin-C was also involved in the control of certain MMPs by tissues) and to perform Kaplan-Meier analyses. Individuals with the highest levels of TNC over-expression ( $>6$-fold) have a highly significant worse prognosis $\left(p<10^{-9}\right.$, logrank test)

GBM cells. The presence of tenascin-C in three-dimensional collagen gels increased the production of MMP-12 by GBM cell lines. Although the cell surface receptor(s) involved remains to be determined, tenascin-C induction of MMP-12 was PKC- $\delta$-dependent, and could have clinical relevance. Indeed, GBM cell invasion was stimulated by tenascin-C-induced MMP-12 and its expression was detected in high-grade GBM [131, 132]. Some mechanistic insight for high tenascin-C expression in gliomas was recently documented [133]. Tissue microarrays revealed a high prevalence of tenascin- $\mathrm{C}$ coexpression with RBPJk protein, a transcriptional cofactor of Notch2, in GBM samples. Tenascin-C expression in GBM cells was explained by RBPJk/Notch2 dependent transactivation and finally, knocking down RBPJk significantly reduced tenascin-C expression and decreased GBM cell motility.

\section{Tenascin-C expression in other cancers}

Tenascin- $\mathrm{C}$ was reported as an indicator of bad prognosis in other tumor contexts such as head and neck cancers [134, 135]. It was recently confirmed through RT-PCR on 158 paraffin-embedded specimens that high expression of tenascin-C, concomitant to angiopoietin-like 4, was 
predictive for poor prognosis and survival in patients presenting oral tongue squamous cell carcinoma [136]. Tenascin- $\mathrm{C}$ could also represent a promising biomarker in giant cell tumors of bones since an elevated tenascin- $\mathrm{C}$ level, assessed by microarray analysis and immunohistochemistry, was shown to have predictive value for both local recurrence and metastasis of these highly aggressive cancers [137]. Interestingly, strong immunofluorescent staining of the FNIII A1 domain of tenascin-C has recently been observed in a large set of non-Hodgkin and Hodgkin lymphomas [138]. The same authors reported a strong reactivity for this tenascin- $\mathrm{C}$ isoform in tumor-associated vasculature of renal cell carcinomas and atypical carcinoid of the lung [139].

\section{Tenascin- $\mathrm{C}$ in tumor angiogenesis}

Tumor angiogenesis is one of the hallmarks of cancer [140]. In order to grow, a tumor needs to trigger angiogenesis, an event that has been termed "the angiogenic switch", which represents an imbalance from anti- to proangiogenic factors driving the transition from a dormant and poorly perfused to a proliferating and vascularized tumor. The angiogenic switch can be triggered by hypoxia, several stromal and tumor cells, and ECM compounds of the reactive tumor microenvironment [141]. The tumor neovasculature usually exhibits severe abnormalities: vessels are tortuous and can be leaky due to poor endothelial cell intercellular cohesion, partial pericyte coverage and a disorganized basement membrane. These chaotic features can be favorable for immune cell infiltration that may promote reactivity of the tumor stroma and may provide conducive gateways for motile tumor cells. A large number of studies were thus devoted to design anti-angiogenic strategies aiming at starving tumors and inducing their subsequent shrinkage. Some of them have been clinically approved, one of the most frequently applied being bevacizumab (or Avastin ${ }^{\circledR}$, a VEGF-blocking humanized antibody). However, anti-angiogenic treatments have demonstrated partial efficacy in certain cancers where resistance and escape mechanisms can occur and were sometimes shown to promote metastasis. In such cases, angiogenesis-targeting cancer treatments have now been revisited and redirected towards tumor vascular normalization in order to optimize anti-cancer drug delivery [142]. ECM proteins, such as cellular fibronectin ( $\mathrm{cFN})$ and tenascin- $\mathrm{C}$, have demonstrated promising potential in tumor vascular targeting [143]. Hereafter are presented recent data illustrating the crucial impact of tenascin-C on tumor angiogenesis and some emerging concepts that could be instrumental for the development of new clinical strategies targeting the tumor vasculature.
Tenascin-C as specific marker of the tumor vasculature

Tenascin-C has previously been specifically observed at perivascular location in GBM [127] and it was proposed that different splicing isoforms could be deposited around tumorsupplying blood vessels in specific patterned manner [1, 143, 144]. In gliomas, blood vessel localization of tenascin-C has recently been confirmed [145]. Due to clear codistribution with desmin-expressing cells, it was also speculated that pericytes could be a source of tenascin-C. Tenascin-C presence in the vascular bed is likely to influence maturation of tumor vessels and could exert both scaffolding and remodeling functions during early steps of tumor vessel formation. Consistently, a strong immunoreactivity for tenascin- $\mathrm{C}$ has been reported in renal cell carcinomas and lung cancers in close vicinity to CD31-positive endothelial cells [139]. Remarkably, EDB (extradomain B)-containing cFN (cellular or oncofetal fibronectin) and tenascin-C exhibited a stratified distribution pattern in tumor vessels, $\mathrm{cFN}$ being mostly found at the luminal and tenascin- $\mathrm{C}$ at the extraluminal site.

Two independent recent studies have been dedicated to tumor vascular marker screening through proteomic approaches [146, 147]. Both studies reported a positive match for tenascin-C in vascular structures of different tumor models. The first study was based on a syngenic heterotopic model of colon carcinoma cell metastasis to the liver [146]. After in vivo biotinylation and purification of proteins accessible to blood perfusion, liver samples were analyzed and compared to healthy animals. Tenascin-C large isoforms (A1/A2/A4 or B domain-containing spliced variants) were specifically found in metastasis-bearing liver samples. The second study was based on laser capture microdissection of vascular structures from invasive ductal breast carcinoma tissue followed by mass spectrometry [147]. Here, tumor vessel-enriched samples were compared to the adjacent nonmalignant tissue to specify a protein signature of tumor microvessels. This signature consisted of 86 overexpressed proteins, including tenascin-C. These approaches represent a significant contribution to our understanding of the proteome and its rearrangements occurring in the tumor vasculature. Finally, they strongly reinforce the notion that tenascin-C is a robust tumor vessel marker that could be used for cancer imaging and clinical interventions.

\section{Potential functions of tenascin- $\mathrm{C}$ in regulating angiogenesis}

Direct functions of tenascin-C in normal and tumor vasculatures

Tenascin- $\mathrm{C}$ has been related for a long time to angiogenesis in various physiological and pathological contexts, 
including cancer [1]. Its ablation significantly reduced neovascularization in a murine corneal injury model induced by cauterization [148]. This was explained by suppression of VEGF and TGF- $\beta 1$ expression by stromal fibroblasts and reduced macrophage infiltration at the injury site. A high perivascular tenascin-C expression was recently associated with cerebral arteriovenous malformations, a pathology characterized by direct connections between arteries, draining veins and cerebral parenchyma which are responsible for subarachnoid bleeding [149]. Tenascin-C null mice exhibited a weaker post-aortotomic neointimal hyperplasia than their wild-type counterparts [63], and deficient revascularization of post-ischemic heart resulting from reduced endothelial progenitor cell recruitment [150]. The past literature on the role of tenascin-C in angiogenesis and vasculogenesis has been reviewed elsewhere [1], and therefore, here new literature will be described in context of previous results. It has previously been demonstrated that tenascin-C can regulate the expression of proangiogenic factors relevant to cancer outcome, including the prototypic angiogenic cytokine VEGF-A [151]. In this study, A375 melanoma cells cocultivated with embryonic stem cells isolated from tenascin-C null mice secreted a significantly reduced amount of VEGF-A as compared to the wild-type condition, suggesting a tenascin-C dependent stromal-induced angiogenic loop. When subcutaneously transplanted, tumors originated from melanoma cells presented a net decrease of capillary numbers in the absence of host tenascin-C. It is likely that stromal and tumor cell-derived tenascin-C controls other potent angiogenic signaling, for example, such as EDNR-A and EDNR-B (endothelin receptors type A and B) and PDGF-BB expression and signaling, notably in glioma cells $[1,152,153]$.

A direct function of tenascin-C in the control of vascular instability of tumor vessels could rely on its well-referenced action in ECM remodeling. A paradigm of a combined action of two matrix molecules on tissue remodeling has been described for tenascin-C and cFN (reviewed in van Obberghen-Schilling et al. 2011). These two ECM proteins are frequently codistributed in dynamic vascular structures and growing evidence suggests that they have overlapping patterns of expression around tumor vessels [139]. We presume that these histological observations might not be fortuitous, especially during tumor angiogenesis. Cryptic motifs of tenascin-C comprised in its FNIII repeat domain were recently shown to interfere with fibronectin fibrillogenesis, and its carboxy-terminal FBG domain is able to potentiate its cellular uptake [27]. Fibronectin can exert a stabilizing function in capillary morphogenesis maturation and functions as a signaling platform in cell presentation of angiogenic cytokines [154, 155]. Considering the well-documented counter adhesive actions of tenascin-C on fibronectin substrata [1], it is possible that specific tenascin- $\mathrm{C}$ domains are unmasked in the perivascular bed of a tumor due to binding of tenascin$\mathrm{C}$ to fibronectin or other ECM molecules. A large isoform of tenascin-C was induced in fibrosarcoma cells upon knock down of $S$-adenosylmethionine decarboxylase and in vivo, aberrantly organized tumor vessels were found surrounding the xenografted tumor cells [156]. Hypoxic stress is a hallmark of tumor stroma that can foster the angiogenic switch of tumors by inducing a genetic reprogramming of stromal and tumor cells leading to increased production of proangiogenic factors [140]. One study had reported that tenascin-C expression can be induced by hypoxic stress and support branching morphogenesis of fetal lung explants [157]. Interestingly, tenascin-C expression was recently correlated with hypoxia and lymph node metastasis of medullary thyroid carcinomas [158]. Wnt signaling represents a proangiogenic pathway that seems to be triggered by tenascin-C. Wnt emerged as prominent morphogenic signal controlling sprouting angiogenesis in a wide array of physiopathological contexts $[159,160]$. Tenascin-C was shown to control the expression of the Wnt antagonist DKK-1 in a GBM cell line [161]. More recently, a decreased expression of a DKK-2 homologue was detected in tenascin-C-deficient MEFs comparing to the wild-type level, suggesting high DKK2 expression in the presence of tenascin-C [162]. As DKK-1 and DKK-2 were shown to exert opposite effects on angiogenesis with DKK-1 inhibiting and DKK-2 stimulating angiogenesis, a potential function of tenascin- $\mathrm{C}$ in the regulation of this balance in tumor-associated endothelial cells would warrant an indepth assessment [99].

GBM certainly represent a model of choice to further characterize the proangiogenic functions of tenascin-C. GBM exhibit a strong plasticity, which could explain the frequently observed resistance to traditional anti-cancer drugs and anti-angiogenic treatment. In addition to sprouting angiogenesis alternative vascularization mechanisms that comprise vascular cooption, angioblast vasculogenesis, intussusceptive microvascular growth, and vasculogenic mimicry are found in GBM [163]. Understanding tenascin-C-associated angiogenesis in GBM could therefore be instrumental in unraveling the many functions of tenascin-C in tumor vessel plasticity, which could be useful in the development of novel therapeutic opportunities [164, 165].

\section{Tenascin-C-enriched matrix channels}

In certain tumor models, stroma-incorporated tenascin-C can be found in tube-shaped structures characterized by fibrillar patterns. Seminal observations of these "matrix channels" were made in aggressive melanoma, which have 
strong expression of tenascin-C that correlated with lymph node metastasis. Tenascin-C was distributed in a tubular meshwork, together with fibronectin and procollagen-I, which wrapped around melanoma cell nests containing erythrocytes [166]. The presence of red blood cells in matrix channels suggested that these structures could form a continuum between vascular and avascular areas of tumor tissue. This consideration also intuitively led to the assumption that tenascin-C-enriched matrix channels could serve as the primary scaffold for tumor angiogenesis and might serve in vascular cooption. A parallel could be drawn to the concept of vasculogenic mimicry, which initially referred to the ability of aggressive melanoma to form vascular conduits through expression of endothelial features by tumor cells [167].

Tenascin-C is physiologically abundant in reticular fibers of lymphoid organs [168-170]. These ECM-rich conduits have been proposed to have crucial functions in the education, maturation, and traffic of immune cells [47]. A recent study has confirmed the specific localization of tenascin- $\mathrm{C}$ in the reticular fibers of the lymph node cortex and proposed that these conduits could constitute permissive paths for lymphocyte migration [171]. A provocative, but not less compelling hypothesis resulting from these observations is a potential role of tenascin- $\mathrm{C}$ in regulating cell trafficking not only in the lymph node but also during tissue repair and in cancer tissue by influencing the recruitment of circulating cells from the blood stream. This possibility is supported by the observation that recruitment of endothelial progenitor cells into an area of revascularization after ischemia is impaired in tenascin- $\mathrm{C}$ null mice [150].

Tenascin-C-enriched matrix channels could also be relevant for tumor cell metastagenicity by providing guiding cues promoting tumor cell escape. It is noteworthy that the tenascin-C-containing matrix channels were qualified as an "invasion-associated fibrillar network" [166]. Tumor cells and fibroblast outgrowing from tumor tissues by using a mesenchymal type of invasion have been imaged through high-resolution time-lapse imaging of organotypic 3D cultures of tumor spheroids [172, 173]. Depending on the tumor, different modes of invasion were observed. Pioneer invading cells can leave the tumor mass in a single cell ECM remodeling invasion mode. Resulting lytic paths were shown to be colonized by trailing squamous cell carcinoma cells, which can individually or collectively take advantage of these preformed ECM tubes to disseminate [172]. It is likely that matrix channels are reminiscent manifestations of past invasive cell movements. Moreover, a potential ascendance and common feature of matrix channels with vascular structures might be instrumental in providing guiding cues for sprouting angiogenesis, or other neovascularization modes.
Melanoma cells were reported to use the abluminal side of tumor vessels when leaving primary tumors [174]. It is tempting to speculate that tenascin-C-enriched matrix channels could fuel similar tropisms in GBM and other cancers.

Finally, matrix channels could constitute protective niches for tumor and stromal cells. By providing specific fibrillar ECM micropatterns, tenascin-C-enriched tubular structures are likely to confine and select tumor and stromal cell subpopulations and could therefore be relevant for driving specific cellular functions and directing differentiation status that could be advantageous for tumor stem cells during treatment with anti-cancer drugs. Tenascin-C was involved in the recruitment of bone-marrow-derived endothelial progenitor cells at injury sites for revascularization [150]. This mode of control of neovessel formation has not been investigated in the tumor context in depth. Tenascin-C was recently detected in subpopulations of a tumor that had demonstrated resistance to anti-cancer drug treatment and has been involved in tumor-derived endothelial cell selection [114, 115]. Tenascin-C would thus possibly emerge as a targetable molecule in highly adaptive cancers resistant to conventional treatments.

\section{Immunomodulatory functions of tenascin-C in cancer}

Several immunomodulatory functions were ascribed to tenascin- $\mathrm{C}$ in various contexts, including early responses to pathogens, injury, and chronic inflammation (reviewed in [47]). Tenascin-C is involved in the regulation of both innate and adaptive immune systems and was shown to control the expression of various cytokines and the recruitment of immune cells into inflammatory or injury sites [48, 148]. Tenascin-C may also have immunomodulatory functions in the tumor context, although there is limited data available. In support of this possibility, it was found that in PyMT induced murine mammary cancer, the number of infiltrating monocytes and macrophages was increased in a tenascin- $C$ null background [175]. Tenascin$\mathrm{C}$ ablation was also seen to provide protection against chronic inflammation, such as in rheumatoid arthritis [48] or in bronchial asthma in the mouse [176]. It has recently been shown that tenascin-C produced by GBM cell lines can inhibit transmigration of $\mathrm{CD}^{+} \mathrm{T}$ lymphocytes through a monolayer of tumor cells in vitro [114]. This effect seemed specific to GBM since it was not seen in monolayers of hepatocellular or breast carcinoma cell lines. It was also described that $\mathrm{T}$ cells required a tenascin-C/ERKMAPK-dependent amoeboid-like morphological adaptation to become polarized for transmigration. Interestingly, $\mathrm{CD} 3+\mathrm{T}$ cell were found accumulated in blood vessels surrounded by tenascin- $\mathrm{C}$ in glioma tissue. Assuming that tenascin- $\mathrm{C}$ emerges as a vascular marker in certain tumors, 
it is likely to influence the recruitment of circulating cells in the stroma. Tenascin- $\mathrm{C}$ expression in tumor stroma appears to also play a critical role in innate immunity modulation. This concept is supported by the contribution of tenascin-C to chronic inflammatory situations [47] and by studies having described its impact on tumor infiltration by monocytes and macrophages [175]. In some studies, tenascin-C has demonstrated specificity in recruiting macrophages versus other myeloid cells to the injury site [148]. It is noteworthy that chronic inflammation is another hallmark of cancer [140], and myeloid lineage cells can support neovascularization by releasing proangiogenic cytokines in the tumor stroma [177].

In light of recent advances that illustrated tenascin-C perivascular expression in tumor vessels, expression in tumor nests connected to the blood circulation and its influence on immune cell infiltration in tumors, an improved understanding of the role of tenascin- $\mathrm{C}$ in tumor homing of bone marrow-derived cells could open important perspectives for designing novel anti-angiogenic therapies.

Tenascin-C as a target for anti-cancer treatment: new tools for imaging and clinical management of cancer

As stromal and tumor vascular markers, relevant for numerous aggressive cancers, large isoforms of tenascin-C have been envisaged as a powerful anti-cancer target for many years. Without stating exhaustively past and present results of these approaches, we propose a short review of imaging and clinical strategies that have been designed and will discuss recent data that could give future perspectives for anti-cancer drug design based on our knowledge about tenascin-C.

Tenascin-C-targeting strategies include silencing approaches, in situ imaging of its expression through immunofluorescent and radiolabeled probes suitable for immuno-PET and MRI contrasting, and delivery of cytokines or radionuclides using tenascin-C-specific antibody or aptamers (summarized in Table 2). An antibody specific for FNIIIC domain of tenascin-C, in SIP format (phagedeveloped small immunoprotein) had proven to be useful for selective delivery of radioiodine and interleukine- 2 to U87 glioma cell-based tumor grafts in mice [178]. An effective regression of U87 gliomas was also observed with anti-FNIIIA1 and anti-FNIIID SIP antibodies (F16 and P12, respectively) [144]. A clinical study based on ${ }^{131} \mathrm{I}$-(81C6)-coupled anti-tenascin-C administration, adjuvant to temozolomide (the standard treatment for GBM), in malignant gliomas, proved good tolerance in GBM patients and was pursued in a randomized trial [179]. This antibody was also tested as a vector for $\alpha$-emitting particles in malignant brain tumors and demonstrated no neurotoxicity, specific local delivery, and, despite a too small number of patients, an encouraging median survival time for GBM patients, as compared to other treatment [180]. Neuradiab ${ }^{\circledR}$ (Bradmer Pharmaceuticals, Inc.), the commercial name of the 81C6 anti-tenascin-C antibody is currently in phase II trials in combination with Avastin ${ }^{\circledR}$ in patients with GBM but results have not yet been published. In another study with 46 GBM patients, double-strand RNA directed against tenascin-C was directly injected into the surgical cavity after tumor resection. This approach showed improved quality of life and significant efficacy, as compared to standard brachytherapy, by increasing overall survival time of 13.2 and 13.9 weeks for grade III gliomas and GBM, respectively [181].

Tissue staining with the F16 SIP antibody revealed high tenascin-C expression in non-small cell lung carcinomas, human Hodgkin or non-Hodgkin lymphomas, renal cell carcinomas, or head and neck cancers, with tumor-specific stromal and vascular patterns [138, 139, 182-184]. The F16 antibody coupled to interleukin-2 (IL-2) was recently shown to significantly improve therapeutic benefit obtained with paclitaxel or doxorubicine treatments in a mouse xenograft model of human breast cancer [185]. Breast cancer patients are currently recruited in phase I/II trials for administration of F16-Il-2 combined with paclitaxel or doxorubicine, or as single treatment with ${ }^{131} \mathrm{I}$-F16. It is becoming clear that tumor-, patient-, stage-specific information on expression patterns of tenascin-C isoforms could be helpful for therapy decisions.

An additional emerging alternative to these antibodybased tenascin-C-targeting strategies, which can present the major drawback of being mono-specific, could consist in the design of multimodal nanoparticles. In such approaches, particles functionalized with aptamers present several advantages. Adjustable and applicable for multiple tumor marker specificity, they could limit off-target effects in normal tissue or towards stromal cells that exert anticancer functions, and are suitable for fluorescence and nuclear imaging as well. One recent study presented a novel multimodal nanoparticle which has been called SMART (for simultaneous multiple aptamers and RGD targeting) [186]. It combines triple affinity for nucleolin, RGD-containing integrins and tenascin- $\mathrm{C}$ and demonstrated higher affinity for cell surface of different cancer cells than single aptamers. Although not yet tested in preclinical studies, this kind of strategy presents a promising opportunity and could be developed into clinical applications in the near future. Altogether, these recent advances should undoubtedly improve the accuracy of anticancer drug delivery, could present great potential for counteracting anti-angiogenic resistance, and have already opened new therapeutic avenues in clinical targeting of cancer. 
Table 2 Tenascin-C targeting in anti-cancer therapies

\begin{tabular}{|c|c|c|c|c|}
\hline Cancer type & Strategy & Stage & Result/outcome & $\overline{\text { Reference }}$ \\
\hline $\begin{array}{l}\text { Mouse orthotopic } \\
\text { xenograft-U87 } \\
\text { human GBM-A375 } \\
\text { human melanoma }\end{array}$ & $\begin{array}{l}\text { F16 (anti-domain A1) and P12 } \\
\text { (anti-domain C) anti-tenascin-C } \\
\text { antibodies administration }\end{array}$ & Preclinic & Tumor-specific targeting of F16 antibody & {$[144]$} \\
\hline $\begin{array}{l}\text { Mouse subcutaneous } \\
\text { and rat orthotopic } \\
\text { xenografts, U87 } \\
\text { human GBM }\end{array}$ & $\begin{array}{l}\text { G11 (anti-domain C) anti-tenascin- } \\
\text { C SIP antibody coupled to IL-2 } \\
\text { or radioiodinated }\end{array}$ & Preclinic & $\begin{array}{l}\text { Selective tumor uptake and } \\
\text { immunoreactivity }\end{array}$ & {$[178]$} \\
\hline $\begin{array}{l}\text { Mouse orthotopic } \\
\text { xenografts-U87 } \\
\text { human GBM }\end{array}$ & $\begin{array}{l}\text { F16 antibody coupled to IL-2- } \\
\text { combination with temozolomide }\end{array}$ & Preclinic & $\begin{array}{l}\text { Tumor growth inhibition-prolonged } \\
\text { survival }\end{array}$ & {$[200]$} \\
\hline $\begin{array}{l}\text { Mouse xenografts- } \\
\text { MDA-MB- } 231 \\
\text { human breast cancer } \\
\text { cells }\end{array}$ & $\begin{array}{l}\text { F16 antibody coupled to IL-2- } \\
\text { combination with doxorubicine } \\
\text { or paclitaxel }\end{array}$ & $\begin{array}{l}\text { Preclinic_-currently } \\
\text { recruiting patients in } \\
\text { phase I/II breast } \\
\text { cancer }\end{array}$ & $\begin{array}{l}\text { Increased benefits (reduced tumor growth/ } \\
\text { prolonged survival) compared to } \\
\text { uncoupled IL-2-improved benefits } \\
\text { with chemotherapy }\end{array}$ & [185] \\
\hline $\begin{array}{l}\text { Human malignant } \\
\text { glioma patients }\end{array}$ & $\begin{array}{l}{ }^{131} \text { I-81C6 anti-tenascin-C } \\
\text { antibody-injection in surgical } \\
\text { resection cavity -radiotherapy- } \\
\text { temozolomide }\end{array}$ & $\begin{array}{l}\text { Clinic-tested in phase III } \\
\text { trials } \\
\text { (unpublished)other } \\
\text { phase I/II ongoing }\end{array}$ & Good tolerance to treatment & {$[179]$} \\
\hline $\begin{array}{l}\text { Human malignant brain } \\
\text { tumors }\end{array}$ & $\begin{array}{l}\text { Alpha-particle emitting astatine- } \\
\text { 221-coupled 81C6 anti-tenascin- } \\
\text { C-injection in surgical cavity }\end{array}$ & $\begin{array}{l}\text { Clinic currently in phase } \\
\text { I/II patients with } \\
\text { primary or metastatic } \\
\text { brain tumors }\end{array}$ & No detectable neurotoxicity & {$[180]$} \\
\hline $\begin{array}{l}\text { Human brain tumors- } \\
\text { GBM }\end{array}$ & $\begin{array}{l}\text { siRNA against tenascin-C- } \\
\text { application in post surgical } \\
\text { resection cavity }\end{array}$ & Clinic & $\begin{array}{l}\text { Improved survival as compared to } \\
\text { brachytherapy-improved quality of } \\
\text { life }\end{array}$ & {$[181]$} \\
\hline $\begin{array}{l}\text { Various human cancer } \\
\text { cell lines }\end{array}$ & $\begin{array}{l}\text { Multimodal nanoparticles with } \\
\text { tenascin-C aptamers } \\
\text { (cospecificity for nucleolin and } \\
\text { RGD-dependent integrins) }\end{array}$ & $\begin{array}{l}\text { Not tested for clinical } \\
\text { applications }\end{array}$ & $\begin{array}{l}\text { Increased cell surface specificity as } \\
\text { compared to single aptamers }\end{array}$ & [201] \\
\hline
\end{tabular}

\section{Imaging of tenascin- $\mathrm{C}$ in cardiac pathologies and atherosclerosis}

Imaging tenascin-C in cardiac pathology

Given the significant correlation between high local and systemic tenascin-C expression and poor cardiac function, much interest has been stimulated in imaging tenascin-C expression during heart disease. After intravenous administration of an anti-tenascin-C antibody labeled with ${ }^{111}$ Indium into rats with experimental autoimmune myocarditis, Sato and collaborators were able to image the distribution of the antibody using a biotracer. The antibody was rapidly cleared from the bloodstream but uptake was significantly enhanced in the myocardium of rats with myocarditis by $6 \mathrm{~h}$ and maintained up to $48 \mathrm{~h}$. High radioactivity was observed specifically in the inflammatory lesions and single-photon emission CT imaging demonstrated the focal myocardial uptake of 111In anti-TNC Fab' occurred during disease [14]. More recently, Taki and collaborators used an $\mathrm{I}^{125}$-labeled tenascin-C antibody to demonstrate the feasibility of spatiotemporal profiling of
tenascin-C expression after myocardial ischemia and reperfusion. Autoradiography of murine heart tissue $24 \mathrm{~h}$ after $20 \mathrm{~min}$ of ischemia and reperfusion revealed significant tenascin-C expression, predominantly in the midmyocardial to endomyocardial layers. Expression peaked at 3 days, and was followed by a marked reduction of tenascin-C expression at 7 days. However, when the ischemia was prolonged to $30 \mathrm{~min}$, the time course of the tenascin-C expression differed considerably; it peaked at 1 and 3 days after reperfusion, and a reduced but still significant expression persisted over 7-14 days, followed by an obvious decline in tenascin- $\mathrm{C}$ expression at 28 days [12]. Finally, a tenascin-C Fab has also been used to detect $\mathrm{LV}$ remodeling during cardiac repair after $\mathrm{MI}$ in rats, an important prognosticator of patient outcome. The localization of the ${ }^{111}$ In-labeled antibody after intravenous injection by dual-isotope single-photon emission computed tomography was revealed to be significantly higher in the heart tissues. Autoradiography of excised tissue confirmed this finding and additionally demonstrated a specific distribution to infarcted areas compared to non-infarcted, validating the use of this technique in vivo and highlighting 
a potentially novel means to assess cardiac disease status [187]. Together, these data demonstrate that both immunoscintigraphic imaging and measuring serum tenascin-C may provide new non-invasive approaches for the diagnosis of myocardial disease activity.

Imaging atherosclerotic plaques

Methods for imaging atherosclerotic plaques exploiting tenascin-C expression are also emerging. The first clue that this may be useful came from studies examining why gadofluorine $\mathrm{M}$, used during MRI to improve imaging of plaques, confers enhanced specific detection of plaque tissue versus the normal vessel wall. It was found that gadofluorine $M$ specifically accumulates in plaques via several interactions; it can bind to serum albumin, which complex is thought to penetrate into the plaque where it then co-localizes to areas of fibrous ECM accumulation. In vitro analysis by microdialysis demonstrated that gadofluorine $\mathrm{M}$ binds to purified ECM components of the plaque, including collagens and tenascin-C, with a $\mathrm{kD}$ of $\sim 2 \mu \mathrm{M}$ [188]. Subsequently, the antibody G11 which specifically recognizes the alternatively spliced $\mathrm{C}$ domain of tenascin-C, an isoform that is enriched in atherosclerotic plaques, was used to visualize late and inflamed or ruptures plaques in ApoE mice on a high-cholesterol diet. Consistent with other reports that link high tenascin-C expression to late-stage plaques, $\mathrm{I}^{125}$-labeled G11 localized specifically to the plaque lesion by $24 \mathrm{~h}$. Upon ex vivo analysis it was found to coincide with fat-rich areas and macrophage infiltration. Antibodies were cleared from circulation by $24 \mathrm{~h}$, creating a favorable blood:tissue ratio that highlights the potential of this approach in imaging [65]. Finally, antibody $\mathrm{F} 16$, which specifically recognizes the A1 domain of tenascin-C, stained human carotid plaque tissue, but not normal ileac arteries, localizing to regions rich in macrophages, proliferating cells, while much weaker staining was observed in quiescent plaques [189]. These studies highlight potential ways to image active remodeling during plaque progression that could become useful tools in patient diagnosis and disease management. Compared to other available methods including ultrasound, computed tomography, magnetic resonance imaging, and angiography, this method may offer additional molecular insight into plaque status.

\section{Conclusions and future perspectives}

Although tenascin-C is a rather "old" molecule, discovered more than 30 years ago, it still reveals surprises to us, evidenced by recent publications. Due to the modular organization, post-translational modification, and cleavage pattern, there is not only one kind of tenascin- $\mathrm{C}$ molecule in a given tissue, but these different tenascin- $\mathrm{C}$ entities sometimes present simultaneously in the same microenvironment, greatly increasing the complexity of possible interactions. Tenascin- $\mathrm{C}$ is a key molecule in tissue remodeling and its deregulated high expression is causally linked to many diseases, including heart failure, thrombosis, atherosclerosis, and cancer. Mechanistically, tenascin$\mathrm{C}$ can have an impact on the microenvironment through direct interactions with cells and growth factors as well as with other ECM molecules, thus regulating tissue resilience and cell responses such as cell survival, migration, proliferation, stemness, and transdifferentiation. Due to technological advances in the development of tenascin- $\mathrm{C}$ targeting strategies, we are now facing a future where the application of our basic knowledge about tenascin-C can translate into the cure or amelioration of diseases.

Acknowledgements We apologize to all authors whose work could not be mentioned. KSM is supported by funding from Arthritis Research UK. GO is supported by the Institut National du Cancer, Institut National de la Santé et de la Recherche Médicale, Université de Strasbourg, Association pour la Recherche contre le Cancer, Agence National de la recherche and a grant from the Hospital Hautepierre.

Open Access This article is distributed under the terms of the Creative Commons Attribution Noncommercial License which permits any noncommercial use, distribution, and reproduction in any medium, provided the original author(s) and source are credited.

\section{References}

1. Midwood KS, Orend G (2009) The role of tenascin-C in tissue injury and tumorigenesis. J Cell Commun Signal 3(3-4): 287-310

2. Orend G (2005) Potential oncogenic action of tenascin-C in tumorigenesis. Int J Biochem Cell Biol 37(5):1066-1083

3. Dobaczewski M, Gonzalez-Quesada C, Frangogiannis NG (2010) The extracellular matrix as a modulator of the inflammatory and reparative response following myocardial infarction. J Mol Cell Cardiol 48(3):504-511

4. Imanaka-Yoshida K, Hiroe M, Yoshida T (2004) Interaction between cell and extracellular matrix in heart disease: multiple roles of tenascin-C in tissue remodeling. Histol Histopathol 19(2):517-525

5. Imanaka-Yoshida $\mathrm{K}$ et al (2003) The dynamic expression of tenascin- $\mathrm{C}$ and tenascin- $\mathrm{X}$ during early heart development in the mouse. Differentiation 71(4-5):291-298

6. Forsberg E et al (1996) Skin wounds and severed nerves heal normally in mice lacking tenascin-C. Proc Natl Acad Sci USA 93(13):6594-6599

7. Saga $Y$ et al (1992) Mice develop normally without tenascin. Genes Dev 6(10):1821-1831

8. Willems IE, Arends JW, Daemen MJ (1996) Tenascin and fibronectin expression in healing human myocardial scars. J Pathol 179(3):321-325

9. Sato I, Shimada K (2001) Quantitative analysis of tenascin in chordae tendineae of human left ventricular papillary muscle with aging. Ann Anat 183(5):443-448 
10. Laky D, Parascan L (2007) Hibernating myocardium, morphological studies on intraoperatory myocardial biopsies and on chronic ischemia experimental model. Rom J Morphol Embryol 48(4):407-413

11. Duerr GD et al (2011) Comparison of myocardial remodeling between cryoinfarction and reperfused infarction in mice. J Biomed Biotechnol 961298

12. Taki $\mathbf{J}$ et al (2010) Dynamic expression of tenascin-C after myocardial ischemia and reperfusion: assessment by $125 \mathrm{I}$-antitenascin-C antibody imaging. J Nucl Med 51(7):1116-1122

13. Imanaka-Yoshida $\mathrm{K}$ et al (2002) Tenascin- $\mathrm{C}$ is a useful marker for disease activity in myocarditis. J Pathol 197(3):388-394

14. Sato M et al (2002) Detection of experimental autoimmune myocarditis in rats by $111 \mathrm{In}$ monoclonal antibody specific for tenascin-C. Circulation 106(11):1397-1402

15. Correia-Pinto J et al (2009) Time course and mechanisms of left ventricular systolic and diastolic dysfunction in monocrotalineinduced pulmonary hypertension. Basic Res Cardiol 104(5): 535-545

16. Hessel M et al (2009) Pressure overload-induced right ventricular failure is associated with re-expression of myocardial tenascin-C and elevated plasma tenascin-C levels. Cell Physiol Biochem 24(3-4):201-210

17. Suzuki H et al (2010) Tenascin-C is induced in cerebral vasospasm after subarachnoid hemorrhage in rats and humans: a pilot study. Neurol Res 32(2):179-184

18. Franz $M$ et al (2010) Extra cellular matrix remodelling after heterotopic rat heart transplantation: gene expression profiling and involvement of ED-A + fibronectin, alpha-smooth muscle actin and $\mathrm{B}+$ tenascin- $\mathrm{C}$ in chronic cardiac allograft rejection. Histochem Cell Biol 134(5):503-517

19. Schenke-Layland K et al (2009) Cardiomyopathy is associated with structural remodelling of heart valve extracellular matrix. Eur Heart J 30(18):2254-2265

20. Morimoto $S$ et al (2005) Diagnostic utility of tenascin-C for evaluation of the activity of human acute myocarditis. J Pathol 205(4):460-467

21. Tsukada B et al (2009) High prevalence of chronic myocarditis in dilated cardiomyopathy referred for left ventriculoplasty: expression of tenascin $\mathrm{C}$ as a possible marker for inflammation. Hum Pathol 40(7):1015-1022

22. Tamura A et al (1996) Tenascin expression in endomyocardial biopsy specimens in patients with dilated cardiomyopathy: distribution along margin of fibrotic lesions. Heart 75(3):291-294

23. Sato A et al (2006) Serum tenascin-C might be a novel predictor of left ventricular remodeling and prognosis after acute myocardial infarction. J Am Coll Cardiol 47(11):2319-2325

24. Terasaki $F$ et al (2007) Higher serum tenascin-C levels reflect the severity of heart failure, left ventricular dysfunction and remodeling in patients with dilated cardiomyopathy. Circ J 71(3):327-330

25. Fujimoto $\mathrm{N}$ et al (2009) Incremental prognostic values of serum tenascin-C levels with blood B-type natriuretic peptide testing at discharge in patients with dilated cardiomyopathy and decompensated heart failure. J Card Fail 15(10):898-905

26. Aso N, Tamura A, Nasu M (2004) Circulating tenascin-C levels in patients with idiopathic dilated cardiomyopathy. Am J Cardiol 94(11):1468-1470

27. Liabeuf $\mathrm{S}$ et al (2011) High circulating levels of large splice variants of tenascin-C is associated with mortality and cardiovascular disease in chronic kidney disease patients. Atherosclerosis 215(1): 116-124

28. Hessel MH et al (2007) Reverse ventricular remodelling after cardiac resynchronization therapy is associated with a reduction in serum tenascin-C and plasma matrix metalloproteinase-9 levels. Eur J Heart Fail 9(10):1058-1063
29. Nishioka $\mathrm{T}$ et al (2007) Eplerenone attenuates myocardial fibrosis in the angiotensin II-induced hypertensive mouse: involvement of tenascin- $\mathrm{C}$ induced by aldosterone-mediated inflammation. J Cardiovasc Pharmacol 49(5):261-268

30. Siri A et al (1995) Different susceptibility of small and large human tenascin-C isoforms to degradation by matrix metalloproteinases. J Biol Chem 270(15):8650-8654

31. Chiao YA et al (2010) In vivo matrix metalloproteinase-7 substrates identified in the left ventricle post-myocardial infarction using proteomics. J Proteome Res 9(5):2649-2657

32. Zamilpa $\mathrm{R}$ et al (2010) Proteomic analysis identifies in vivo candidate matrix metalloproteinase- 9 substrates in the left ventricle post-myocardial infarction. Proteomics 10(11):2214-2223

33. Saito $\mathrm{Y}$ et al (2007) A peptide derived from tenascin-C induces beta1 integrin activation through syndecan-4. J Biol Chem 282(48):34929-34937

34. Ambort D et al (2010) Specific processing of tenascin-C by the metalloprotease meprinbeta neutralizes its inhibition of cell spreading. Matrix Biol 29(1):31-42

35. To WS, Midwood KS (2010) Cryptic domains of tenascin-C differentially control fibronectin fibrillogenesis. Matrix Biol 29(7):573-585

36. To WS, Midwood KS (2011) Identification of novel and distinct binding sites within tenascin-C for soluble and fibrillar fibronectin. J Biol Chem 286(17):14881-14891

37. Tucker RP, Chiquet-Ehrismann R (2009) The regulation of tenascin expression by tissue microenvironments. Biochim Biophys Acta 1793(5):888-892

38. Chiquet $\mathrm{M}$ et al (2009) From mechanotransduction to extracellular matrix gene expression in fibroblasts. Biochim Biophys Acta 1793(5):911-920

39. Yamamoto $\mathrm{K}$ et al (1999) Induction of tenascin-C in cardiac myocytes by mechanical deformation. Role of reactive oxygen species. J Biol Chem 274(31):21840-21846

40. Jiang L et al (2009) Synergistic effects of cyclic strain and Th1like cytokines on tenascin-C production by rheumatic aortic valve interstitial cells. Clin Exp Immunol 155(2):216-223

41. Chiquet-Ehrismann R, Chiquet M (2003) Tenascins: regulation and putative functions during pathological stress. J Pathol 200(4):488-499

42. Chiquet-Ehrismann $\mathrm{R}$ et al (1988) Tenascin interferes with fibronectin action. Cell 53(3):383-390

43. Huang $\mathrm{W}$ et al (2001) Interference of tenascin- $\mathrm{C}$ with syndecan4 binding to fibronectin blocks cell adhesion and stimulates tumor cell proliferation. Cancer Res 61(23):8586-8594

44. Murphy-Ullrich JE et al (1991) Focal adhesion integrity is downregulated by the alternatively spliced domain of human tenascin. J Cell Biol 115(4):1127-1136

45. Orend $\mathrm{G}$ et al (2003) Tenascin-C blocks cell-cycle progression of anchorage-dependent fibroblasts on fibronectin through inhibition of syndecan-4. Oncogene 22(25):3917-3926

46. Imanaka-Yoshida $\mathrm{K}$ et al (2001) Tenascin-C modulates adhesion of cardiomyocytes to extracellular matrix during tissue remodeling after myocardial infarction. Lab Invest 81(7):1015-1024

47. Udalova IA et al. (2011) Expression and immune function of tenascin-C. Crit Rev Immunol 31(2):115-145

48. Midwood K et al (2009) Tenascin-C is an endogenous activator of Toll-like receptor 4 that is essential for maintaining inflammation in arthritic joint disease. Nat Med 15(7):774-780

49. Kanayama M et al (2009) Alpha9 integrin and its ligands constitute critical joint microenvironments for development of autoimmune arthritis. J Immunol 182(12):8015-8025

50. Hanamura $\mathrm{N}$ et al (1997) Expression of fibronectin and tenascinC mRNA by myofibroblasts, vascular cells and epithelial cells in human colon adenomas and carcinomas. Int $\mathrm{J}$ Cancer 73(1):10-15 
51. Kalembeyi I et al (2003) Tenascin-C upregulates matrix metalloproteinase-9 in breast cancer cells: direct and synergistic effects with transforming growth factor beta1. Int J Cancer 105(1):53-60

52. Yoshida T et al (1997) Co-expression of tenascin and fibronectin in epithelial and stromal cells of benign lesions and ductal carcinomas in the human breast. J Pathol 182(4):421-428

53. Berndt A et al (1994) Appearance of the myofibroblastic phenotype in Dupuytren's disease is associated with a fibronectin, laminin, collagen type IV and tenascin extracellular matrix. Pathobiology 62(2):55-58

54. Tamaoki $\mathrm{M}$ et al (2005) Tenascin-C regulates recruitment of myofibroblasts during tissue repair after myocardial injury. Am J Pathol 167(1):71-80

55. Nishioka $T$ et al (2010) Tenascin-C may aggravate left ventricular remodeling and function after myocardial infarction in mice. Am J Physiol Heart Circ Physiol 298(3):H1072-H1078

56. Bujak M et al (2007) Essential role of Smad3 in infarct healing and in the pathogenesis of cardiac remodeling. Circulation 116(19):2127-2138

57. Huang $\mathrm{Z}$ et al (2009) Defective pulmonary vascular remodeling in Smad8 mutant mice. Hum Mol Genet 18(15):2791-2801

58. El-Karef A et al (2007) Deficiency of tenascin-C attenuates liver fibrosis in immune-mediated chronic hepatitis in mice. J Pathol 211(1):86-94

59. Nakao $\mathrm{N}$ et al (1998) Tenascin-C promotes healing of Habusnake venom-induced glomerulonephritis: studies in knockout congenic mice and in culture. Am J Pathol 152(5):1237-1245

60. Shah M, Foreman DM, Ferguson MW (1994) Neutralising antibody to TGF-beta 1,2 reduces cutaneous scarring in adult rodents. J Cell Sci 107(Pt 5):1137-1157

61. Shah M, Foreman DM, Ferguson MW (1995) Neutralisation of TGF-beta 1 and TGF-beta 2 or exogenous addition of TGF-beta 3 to cutaneous rat wounds reduces scarring. J Cell Sci $108(\mathrm{Pt}$ 3):985-1002

62. Hedin U, Holm J, Hansson GK (1991) Induction of tenascin in rat arterial injury. Relationship to altered smooth muscle cell phenotype. Am J Pathol 139(3):649-656

63. Yamamoto $\mathrm{K}$ et al (2005) Tenascin- $\mathrm{C}$ is an essential factor for neointimal hyperplasia after aortotomy in mice. Cardiovasc Res 65(3):737-742

64. Sawada $\mathrm{Y}$ et al (2007) Tenascin-C synthesized in both donor grafts and recipients accelerates artery graft stenosis. Cardiovasc Res 74(3):366-376

65. von Lukowicz T et al (2007) Human antibody against C domain of tenascin-C visualizes murine atherosclerotic plaques ex vivo. J Nucl Med 48(4):582-587

66. Jones PL, Rabinovitch M (1996) Tenascin-C is induced with progressive pulmonary vascular disease in rats and is functionally related to increased smooth muscle cell proliferation. Circ Res 79(6):1131-1142

67. Wallner K et al (1999) Tenascin-C is expressed in macrophagerich human coronary atherosclerotic plaque. Circulation 99(10):1284-1289

68. Kenji K et al (2004) Tenascin-C is associated with coronary plaque instability in patients with acute coronary syndromes. Circ J 68(3): 198-203

69. Seo D et al (2004) Gene expression phenotypes of atherosclerosis. Arterioscler Thromb Vasc Biol 24(10):1922-1927

70. Qin M et al (2003) Suppression subtractive hybridization identifies distinctive expression markers for coronary and internal mammary arteries. Arterioscler Thromb Vasc Biol 23(3): 425-433

71. Fukumoto $\mathrm{H}$ et al (1998) Immunohistochemical and morphometric evaluations of coronary atherosclerotic plaques associated with myocardial infarction and diabetes mellitus. J Atheroscler Thromb 5(1):29-35

72. Duner $P$ et al (2009) Immune responses against fibronectin modified by lipoprotein oxidation and their association with cardiovascular disease. J Intern Med 265(5):593-603

73. Minear MA et al (2011) Polymorphic variants in tenascin-C (TNC) are associated with atherosclerosis and coronary artery disease. Hum Genet 129(6):641-654

74. Pitman WA et al (1998) Genetic analysis of the difference in diet-induced atherosclerosis between the inbred mouse strains SM/J and NZB/BINJ. Arterioscler Thromb Vasc Biol 18(4): 615-620

75. Wallner K et al (1999) Arterialization of human vein grafts is associated with tenascin-C expression. J Am Coll Cardiol 34(3):871-875

76. Imanaka-Yoshida $\mathrm{K}$ et al (2001) Serial extracellular matrix changes in neointimal lesions of human coronary artery after percutaneous transluminal coronary angioplasty: clinical significance of early tenascin-C expression. Virchows Arch 439(2): $185-190$

77. Ross R, Glomset JA (1976) The pathogenesis of atherosclerosis (second of two parts). N Engl J Med 295(8):420-425

78. Ross R, Glomset JA (1976) The pathogenesis of atherosclerosis (first of two parts). N Engl J Med 295(7):369-377

79. Goh FG et al (2010) Transcriptional regulation of the endogenous danger signal tenascin-C: a novel autocrine loop in inflammation. J Immunol 184(5):2655-2662

80. Wallner $\mathrm{K}$ et al (2001) Adventitial remodeling after angioplasty is associated with expression of tenascin mRNA by adventitial myofibroblasts. J Am Coll Cardiol 37(2):655-661

81. Sharifi BG et al (1992) Angiotensin II regulates tenascin gene expression in vascular smooth muscle cells. J Biol Chem 267(33):23910-23915

82. Wallner K, Shah PK, Sharifi BG (2002) Balloon catheterization induces arterial expression of new Tenascin-C isoform. Atherosclerosis 161(1):75-83

83. Feng Y et al (1999) Transcriptional profile of mechanically induced genes in human vascular smooth muscle cells. Circ Res 85(12): 1118-1123

84. Jones PL et al (2002) Altered hemodynamics controls matrix metalloproteinase activity and tenascin-C expression in neonatal pig lung. Am J Physiol Lung Cell Mol Physiol 282(1):L26-L35

85. Jones PL et al (1999) Induction of vascular smooth muscle cell tenascin-C gene expression by denatured type I collagen is dependent upon a beta3 integrin-mediated mitogen-activated protein kinase pathway and a 122-base pair promoter element. J Cell Sci 112(Pt 4):435-445

86. Jones FS et al (2001) Prx1 controls vascular smooth muscle cell proliferation and tenascin-C expression and is upregulated with Prx2 in pulmonary vascular disease. Circ Res 89(2):131-138

87. Chapados R et al (2006) ROCK controls matrix synthesis in vascular smooth muscle cells: coupling vasoconstriction to vascular remodeling. Circ Res 99(8):837-844

88. LaFleur DW et al (1997) Aortic smooth muscle cells interact with tenascin-C through its fibrinogen-like domain. J Biol Chem 272(52):32798-32803

89. Yokoyama $\mathrm{K}$ et al (2000) Identification of amino acid sequences in fibrinogen gamma -chain and tenascin $\mathrm{C} \mathrm{C}$-terminal domains critical for binding to integrin alpha vbeta 3. J Biol Chem 275(22):16891-16898

90. LaFleur DW et al (1994) Cloning and characterization of alternatively spliced isoforms of rat tenascin. Platelet-derived growth factor-BB markedly stimulates expression of spliced variants of tenascin mRNA in arterial smooth muscle cells. J Biol Chem 269(32):20757-20763 
91. Jones PL, Cowan KN, Rabinovitch M (1997) Tenascin-C, proliferation and subendothelial fibronectin in progressive pulmonary vascular disease. Am J Pathol 150(4):1349-1360

92. Jones PL, Crack J, Rabinovitch M (1997) Regulation of tenascin-C, a vascular smooth muscle cell survival factor that interacts with the alpha $\mathrm{v}$ beta 3 integrin to promote epidermal growth factor receptor phosphorylation and growth. J Cell Biol 139(1):279-293

93. Ishigaki $\mathrm{T}$ et al(2010) Tenascin-C enhances crosstalk signaling of integrin alphavbeta3/PDGFR-beta complex by SRC recruitment promoting PDGF-induced proliferation and migration in smooth muscle cells. J Cell Physiol. doi:10.1002/jcp.22614

94. Watkins H, Farrall M (2006) Genetic susceptibility to coronary artery disease: from promise to progress. Nat Rev Genet 7(3): $163-173$

95. Wallner $\mathrm{K}$ et al (2004) EGF-Like domain of tenascin-C is proapoptotic for cultured smooth muscle cells. Arterioscler Thromb Vasc Biol 24(8):1416-1421

96. Fujinaga $\mathrm{K}$ et al (2004) Locally applied cilostazol suppresses neointimal hyperplasia by inhibiting tenascin-C synthesis and smooth muscle cell proliferation in free artery grafts. J Thorac Cardiovasc Surg 128(3):357-363

97. Cowan KN, Jones PL, Rabinovitch M (2000) Elastase and matrix metalloproteinase inhibitors induce regression, and tenascin-C antisense prevents progression, of vascular disease. $\mathrm{J}$ Clin Invest 105(1):21-34

98. Schaff $\mathrm{M}$ et al (2010) Novel function of tenascin-C, a matrix protein relevant to atherosclerosis, in platelet recruitment and activation under flow. Arterioscler Thromb Vasc Biol 31(1):117-124

99. Brellier $\mathrm{F}$ et al (2011) Tenascin- $\mathrm{C}$ triggers fibrin accumulation by downregulation of tissue plasminogen activator. FEBS Lett 585(6):913-920

100. Cowan KN, Jones PL, Rabinovitch M (1999) Regression of hypertrophied rat pulmonary arteries in organ culture is associated with suppression of proteolytic activity, inhibition of tenascin-C, and smooth muscle cell apoptosis. Circ Res 84(10): $1223-1233$

101. Jian B et al (2001) Matrix metalloproteinase-2 is associated with tenascin-C in calcific aortic stenosis. Am J Pathol 159(1): 321-327

102. Vyavahare $\mathrm{N}$ et al (2000) Inhibition of matrix metalloproteinase activity attenuates tenascin-C production and calcification of implanted purified elastin in rats. Am J Pathol 157(3):885-893

103. Garcion E, Faissner A, ffrench-Constant C (2001) Knockout mice reveal a contribution of the extracellular matrix molecule tenascin-C to neural precursor proliferation and migration. Development 128(13):2485-2496

104. Garcion E et al (2004) Generation of an environmental niche for neural stem cell development by the extracellular matrix molecule tenascin C. Development 131(14):3423-3432

105. Abaskharoun $M$ et al (2010) Glypican-1, phosphacan/receptor protein-tyrosine phosphatase-zeta/beta and its ligand, tenascin$\mathrm{C}$, are expressed by neural stem cells and neural cells derived from embryonic stem cells. ASN Neuro 2(3):e00039

106. von Holst A et al (2007) Neural stem/progenitor cells express 20 tenascin $\mathrm{C}$ isoforms that are differentially regulated by Pax6. J Biol Chem 282(12):9172-9181

107. Yagi $\mathrm{H}$ et al (2010) HNK-1 epitope-carrying tenascin-C spliced variant regulates the proliferation of mouse embryonic neural stem cells. J Biol Chem 285(48):37293-37301

108. Moritz S et al (2008) An induction gene trap screen in neural stem cells reveals an instructive function of the niche and identifies the splicing regulator sam68 as a tenascin-C-regulated target gene. Stem Cells 26(9):2321-2331
109. Najib S et al (2005) Role of Sam68 as an adaptor protein in signal transduction. Cell Mol Life Sci 62(1):36-43

110. Bielli $\mathrm{P}$ et al (2011) The RNA binding protein Sam68 is a multifunctional player in human cancer. Endocr Relat Cancer 18(4):R91-R102

111. Czopka T et al (2010) Regulatory mechanisms that mediate tenascin C-dependent inhibition of oligodendrocyte precursor differentiation. J Neurosci 30(37):12310-12322

112. Ricci-Vitiani L et al (2010) Tumour vascularization via endothelial differentiation of glioblastoma stem-like cells. Nature 468(7325):824-828

113. Wang R et al (2010) Glioblastoma stem-like cells give rise to tumour endothelium. Nature 468(7325):829-833

114. Pezzolo A et al (2011) Oct-4(+)/Tenascin $\mathrm{C}(+)$ neuroblastoma cells serve as progenitors of tumor-derived endothelial cells. Cell Res. Mar 15 Epub ahead of print

115. Fukunaga-Kalabis $\mathrm{M}$ et al (2010) Tenascin-C promotes melanoma progression by maintaining the ABCB5-positive side population. Oncogene 29(46):6115-6124

116. Mackie EJ et al (1987) Tenascin is a stromal marker for epithelial malignancy in the mammary gland. Proc Natl Acad Sci USA 84(13):4621-4625

117. Adams $\mathrm{M}$ et al (2002) Changes in tenascin-C isoform expression in invasive and preinvasive breast disease. Cancer Res 62(11):3289-3297

118. Tsunoda $\mathrm{T}$ et al (2003) Involvement of large tenascin-C splice variants in breast cancer progression. Am J Pathol 162(6): 1857-1867

119. Hancox RA et al (2009) Tumour-associated tenascin-C isoforms promote breast cancer cell invasion and growth by matrix metalloproteinase-dependent and independent mechanisms. Breast Cancer Res 11(2):R24

120. Guttery DS et al Association of invasion-promoting tenascin-C additional domains with breast cancers in young women. Breast Cancer Res 12(4): R57

121. Minn AJ et al (2005) Genes that mediate breast cancer metastasis to lung. Nature 436(7050):518-524

122. Tavazoie SF et al (2008) Endogenous human microRNAs that suppress breast cancer metastasis. Nature 451(7175):147-152

123. Scharer CD et al (2009) Genome-wide promoter analysis of the SOX4 transcriptional network in prostate cancer cells. Cancer Res 69(2):709-717

124. Taraseviciute A et al (2010) Quantitative analysis of threedimensional human mammary epithelial tissue architecture reveals a role for tenascin-C in regulating c-met function. Am J Pathol 176(2):827-838

125. Helleman $\mathrm{J}$ et al (2008) Association of an extracellular matrix gene cluster with breast cancer prognosis and endocrine therapy response. Clin Cancer Res 14(17):5555-5564

126. Leins A et al (2003) Expression of tenascin-C in various human brain tumors and its relevance for survival in patients with astrocytoma. Cancer 98(11):2430-2439

127. Herold-Mende C et al (2002) Clinical impact and functional aspects of tenascin-C expression during glioma progression. Int J Cancer 98(3):362-369

128. Colman $\mathrm{H}$ et al (2011) A multigene predictor of outcome in glioblastoma. Neuro Oncol 12(1):49-57

129. Brellier $\mathrm{F}$ et al (2010) SMOC1 is a tenascin-C interacting protein over-expressed in brain tumors. Matrix Biol 30(3):225-233

130. Hirata E et al (2009) Endogenous tenascin-C enhances glioblastoma invasion with reactive change of surrounding brain tissue. Cancer Sci 100(8):1451-1459

131. Sarkar $\mathrm{S}$ et al (2006) Tenascin-C stimulates glioma cell invasion through matrix metalloproteinase-12. Cancer Res 66(24): 11771-11780 
132. Sarkar S, Yong VW (2010) Reduction of protein kinase C delta attenuates tenascin-C stimulated glioma invasion in threedimensional matrix. Carcinogenesis 31(2):311-317

133. Sivasankaran B et al (2009) Tenascin-C is a novel RBPJkappainduced target gene for Notch signaling in gliomas. Cancer Res 69(2):458-465

134. Lyons AJ, Jones J (2007) Cell adhesion molecules, the extracellular matrix and oral squamous carcinoma. Int $\mathrm{J}$ Oral Maxillofac Surg 36(8):671-679

135. Atula $\mathrm{T}$ et al (2003) Tenascin-C expression and its prognostic significance in oral and pharyngeal squamous cell carcinoma. Anticancer Res 23(3C):3051-3056

136. Wang $\mathrm{Z}$ et al (2011) Expression of angiopoietin-like 4 and tenascin $\mathrm{C}$ but not cathepsin $\mathrm{C}$ mRNA predicts prognosis of oral tongue squamous cell carcinoma. Biomarkers 15(1):39-46

137. Pazzaglia L et al (2010) Differential gene expression in classic giant cell tumours of bone: tenascin $\mathrm{C}$ as biological risk factor for local relapses and metastases. Histopathology 57(1): 59-72

138. Schliemann C et al (2009) Three clinical-stage tumor targeting antibodies reveal differential expression of oncofetal fibronectin and tenascin-C isoforms in human lymphoma. Leuk Res 33(12):1718-1722

139. Berndt A et al (2010) A comparative analysis of oncofetal fibronectin and tenascin-C incorporation in tumour vessels using human recombinant SIP format antibodies. Histochem Cell Biol 133(4):467-475

140. Hanahan D, Weinberg RA (2011) Hallmarks of cancer: the next generation. Cell 144(5):646-674

141. Baeriswyl V, Christofori G (2009) The angiogenic switch in carcinogenesis. Semin Cancer Biol 19(5):329-337

142. Carmeliet P, Jain RK (2011) Principles and mechanisms of vessel normalization for cancer and other angiogenic diseases. Nat Rev Drug Discov 10(6):417-427

143. Neri D, Bicknell R (2005) Tumour vascular targeting. Nat Rev Cancer 5(6):436-446

144. Brack SS et al (2006) Tumor-targeting properties of novel antibodies specific to the large isoform of tenascin-C. Clin Cancer Res 12(10):3200-3208

145. Martina E et al (2010) Tenascin-W is a specific marker of glioma-associated blood vessels and stimulates angiogenesis in vitro. FASEB J 24(3): 778-787

146. Borgia B et al (2010) A proteomic approach for the identification of vascular markers of liver metastasis. Cancer Res 70(1):309-318

147. Hill JJ et al (2011) Identification of vascular breast tumor markers by laser capture microdissection and label-free LC-MS. J Proteome Res 10(5):2479-2493

148. Sumioka $T$ et al (2011) Impaired angiogenic response in the cornea of mice lacking tenascin C. Invest Ophthalmol Vis Sci 52(5):2462-2467

149. Bicer A et al (2010) Expressions of angiogenesis associated matrix metalloproteinases and extracellular matrix proteins in cerebral vascular malformations. J Clin Neurosci 17(2):232-236

150. Ballard VL et al (2006) Vascular tenascin-C regulates cardiac endothelial phenotype and neovascularization. FASEB J 20(6):717-719

151. Tanaka $\mathrm{K}$ et al (2004) Tenascin-C regulates angiogenesis in tumor through the regulation of vascular endothelial growth factor expression. Int J Cancer 108(1):31-40

152. Lange $\mathrm{K}$ et al (2007) Endothelin receptor type B counteracts tenascin-C-induced endothelin receptor type A-dependent focal adhesion and actin stress fiber disorganization. Cancer Res 67(13):6163-6173

153. Lange $\mathrm{K}$ et al (2008) Combined lysophosphatidic acid/plateletderived growth factor signaling triggers glioma cell migration in a tenascin-C microenvironment. Cancer Res 68(17):6942-6952
154. Vouret-Craviari V et al (2004) ILK is required for the assembly of matrix-forming adhesions and capillary morphogenesis in endothelial cells. J Cell Sci 117(Pt 19):4559-4569

155. Hynes RO (2009) The extracellular matrix: not just pretty fibrils. Science 326(5957):1216-1219

156. Paasinen-Sohns A et al (2011) Chaotic neovascularization induced by aggressive fibrosarcoma cells overexpressing $S$ adenosylmethionine decarboxylase. Int $\mathrm{J}$ Biochem Cell Biol 43(3):441-454

157. Gebb SA, Jones PL (2003) Hypoxia and lung branching morphogenesis. Adv Exp Med Biol 543:117-125

158. Koperek $\mathrm{O}$ et al (2011) Expression of hypoxia-associated proteins in sporadic medullary thyroid cancer is associated with desmoplastic stroma reaction and lymph node metastasis and may indicate somatic mutations in the VHL gene. J Pathol 225(1):63-72

159. Dejana E (2010) The role of Wnt signaling in physiological and pathological angiogenesis. Circ Res 107(8):943-952

160. Stefater Iii JA et al (2011) Regulation of angiogenesis by a noncanonical Wnt-Flt1 pathway in myeloid cells. Nature 474: $511-515$

161. Ruiz C et al (2004) Growth promoting signaling by tenascin-C [corrected]. Cancer Res 64(20):7377-7385

162. Brellier $F$ et al (2011) Tenascin- $C$ triggers fibrin accumulation by downregulation of tissue plasminogen activator. FEBS Lett 585(6):913-920

163. El Hallani S et al (2010) A new alternative mechanism in glioblastoma vascularization: tubular vasculogenic mimicry. Brain 133(Pt 4): 973-982

164. Onishi $M$ et al (2011) Angiogenesis and invasion in glioma. Brain Tumor Pathol 28(1): 13-24

165. Lino M, Merlo A (2009) Translating biology into clinic: the case of glioblastoma. Curr Opin Cell Biol 21(2):311-316

166. Kaariainen E et al (2006) Switch to an invasive growth phase in melanoma is associated with tenascin-C, fibronectin, and procollagen-I forming specific channel structures for invasion. J Pathol 210(2):181-191

167. Hendrix MJ et al (2003) Vasculogenic mimicry and tumour-cell plasticity: lessons from melanoma. Nat Rev Cancer 3(6):411-421

168. Lokmic $Z$ et al (2008) The extracellular matrix of the spleen as a potential organizer of immune cell compartments. Semin Immunol 20(1):4-13

169. Link A et al (2011) Association of T-zone reticular networks and conduits with ectopic lymphoid tissues in mice and humans. Am J Pathol 178(4): 1662-1675

170. Drumea-Mirancea M et al (2006) Characterization of a conduit system containing laminin-5 in the human thymus: a potential transport system for small molecules. J Cell Sci 119(Pt 7): 1396-1405

171. Sobocinski GP et al (2010) Ultrastructural localization of extracellular matrix proteins of the lymph node cortex: evidence supporting the reticular network as a pathway for lymphocyte migration. BMC Immunol 11:42

172. Gaggioli $\mathrm{C}$ et al (2007) Fibroblast-led collective invasion of carcinoma cells with differing roles for RhoGTPases in leading and following cells. Nat Cell Biol 9(12):1392-1400

173. Wolf K et al (2007) Multi-step pericellular proteolysis controls the transition from individual to collective cancer cell invasion. Nat Cell Biol 9(8):893-904

174. Lugassy C, Barnhill RL (2007) Angiotropic melanoma and extravascular migratory metastasis: a review. Adv Anat Pathol 14(3):195-201

175. Talts JF et al (1999) Tenascin-C modulates tumor stroma and monocyte/macrophage recruitment but not tumor growth or metastasis in a mouse strain with spontaneous mammary cancer. J Cell Sci 112(Pt 12):1855-1864 
176. Nakahara H et al (2006) Deficiency of tenascin C attenuates allergen-induced bronchial asthma in the mouse. Eur J Immunol 36(12):3334-3345

177. Pollard JW (2004) Tumour-educated macrophages promote tumour progression and metastasis. Nat Rev Cancer 4(1):71-78

178. Silacci M et al (2006) Human monoclonal antibodies to domain $\mathrm{C}$ of tenascin-C selectively target solid tumors in vivo. Protein Eng Des Sel 19(10):471-478

179. Reardon DA et al (2008) A pilot study: 131I-antitenascin monoclonal antibody $81 \mathrm{c} 6$ to deliver a $44-\mathrm{Gy}$ resection cavity boost. Neuro Oncol 10(2):182-189

180. Zalutsky MR et al (2008) Clinical experience with alpha-particle emitting 211At: treatment of recurrent brain tumor patients with 211At-labeled chimeric antitenascin monoclonal antibody 81C6. J Nucl Med 49(1):30-38

181. Rolle K et al (2010) Promising human brain tumors therapy with interference RNA intervention (iRNAi). Cancer Biol Ther 9(5):396-406

182. Schwager K et al (2011) A comparative immunofluorescence analysis of three clinical-stage antibodies in head and neck cancer. Head Neck Oncol 3:25

183. Pedretti M et al (2009) Comparative immunohistochemistry of L19 and F16 in non-small cell lung cancer and mesothelioma: two human antibodies investigated in clinical trials in patients with cancer. Lung Cancer 64(1):28-33

184. Schwager K et al (2011) A comparative immunofluorescence analysis of three clinical-stage antibodies in head and neck cancer. Head Neck Oncol 3:25

185. Marlind J et al (2008) Antibody-mediated delivery of interleukin-2 to the stroma of breast cancer strongly enhances the potency of chemotherapy. Clin Cancer Res 14(20):6515-6524

186. Ko HY et al (2011) A multimodal nanoparticle-based cancer imaging probe simultaneously targeting nucleolin, integrin alphavbeta3 and tenascin-C proteins. Biomaterials 32(4): $1130-1138$

187. Odaka $\mathrm{K}$ et al (2008) Noninvasive detection of cardiac repair after acute myocardial infarction in rats by 111 In Fab fragment of monoclonal antibody specific for tenascin-C. Int Heart $\mathrm{J}$ 49(4):481-492

188. Meding J et al (2007) Magnetic resonance imaging of atherosclerosis by targeting extracellular matrix deposition with Gadofluorine M. Contrast Media Mol Imaging 2(3):120-129

189. Pedretti $M$ et al (2010) Comparative immunohistochemical staining of atherosclerotic plaques using F16, F8 and L19: three clinical-grade fully human antibodies. Atherosclerosis 208(2):382-389

190. Madhavan S et al (2009) Rembrandt: helping personalized medicine become a reality through integrative translational research. Mol Cancer Res 7(2):157-167

191. Celik A et al (2011) Tenascin-C may be a predictor of acute pulmonary thromboembolism. J Atheroscler Thromb 18(6): 487-493

192. Majumdar R et al (2007) Elevated expressions of osteopontin and tenascin $\mathrm{C}$ in ascending aortic aneurysms are associated with trileaflet aortic valves as compared with bicuspid aortic valves. Cardiovasc Pathol 16(3):144-150

193. Della Corte A et al (2008) Spatiotemporal patterns of smooth muscle cell changes in ascending aortic dilatation with bicuspid and tricuspid aortic valve stenosis: focus on cell-matrix signaling. J Thorac Cardiovasc Surg 135(1): 8-18, 18 e1-2

194. Franz M et al (2009) Serum levels of large tenascin-C variants, matrix metalloproteinase- 9 , and tissue inhibitors of matrix metalloproteinases in concentric versus eccentric left ventricular hypertrophy. Eur J Heart Fail 11(11):1057-1062

195. Milting $\mathrm{H}$ et al (2008) Plasma biomarkers of myocardial fibrosis and remodeling in terminal heart failure patients supported by mechanical circulatory support devices. J Heart Lung Transplant 27(6):589-596

196. Frangogiannis NG et al (2002) Active interstitial remodeling: an important process in the hibernating human myocardium. J Am Coll Cardiol 39(9):1468-1474

197. Donato $G$ et al (2009) Expression of tenascin-C and CD44 receptors in cardiac myxomas. Cardiovasc Pathol 18(3):173-177

198. Schumann C et al (2010) Circulating biomarkers of tissue remodelling in pulmonary hypertension. Biomarkers 15(6): 523-532

199. Franz M et al (2010) Changes in extra cellular matrix remodelling and re-expression of fibronectin and tenascin-C splicing variants in human myocardial tissue of the right atrial auricle: implications for a targeted therapy of cardiovascular diseases using human SIP format antibodies. J Mol Histol 41(1):39-50

200. Pedretti $M$ et al (2010) Combination of temozolomide with immunocytokine F16-IL2 for the treatment of glioblastoma. Br J Cancer 103(6):827-836

201. Ko HY et al (2011) A multimodal nanoparticle-based cancer imaging probe simultaneously targeting nucleolin, integrin alphavbeta3 and tenascin-C proteins. Biomaterials 32(4): $1130-1138$ 